Review

\title{
T and B Cell Metabolism in Older Adults
}

\author{
Ying Zhang ${ }^{1,2}$, Hildegund C. J. Ertl ${ }^{3, *}$ \\ 1 Program in Cellular and Molecular Medicine, Boston Children's Hospital, \\ Boston, MA 02115, USA \\ 2 Department of Pediatrics, Harvard Medical School, Boston, MA 02115, USA \\ 3 The Wistar Institute, Philadelphia, PA 19104, USA \\ * Correspondence: Hildegund C. J. Ertl, Email: ertl@wistar.org; \\ Tel.: +1-215-898-3863.
}

\begin{abstract}
Immunosenescence, a process that describes age-related declines in immune responses, renders the elderly more susceptible to infections and malignancies. Many changes that accumulate during aging contribute to immunosenescence and one of them is a decline in metabolic fitness. Here we discuss how aging affects functions and metabolism of cells of the adaptive immune system. Both $\mathrm{T}$ and $\mathrm{B}$ cells once they become activated have to rapidly adjust their metabolism to allow for cell proliferation and effector functions. In younger adults most $\mathrm{T}$ cell subsets switch to glycolysis upon activation, while $B$ cells, in addition, increase mitochondrial energy production. Once lymphocytes transition towards memory, they again must adjust their metabolism. These metabolic switches, which are prompted by a number of signaling pathways that concomitantly regulate mitochondrial biogenesis, protein translation, and glycosylation pathways, as well as protein transport and autophagy, become impaired in the aged. As a result, invasion of a pathogen commonly triggers low quality effector $\mathrm{T}$ and $\mathrm{B}$ cell responses that, compared to those in younger individuals, are less potent, less functional, and less broad. Formation of memory also becomes impaired, reducing the benefits of vaccines in the elderly.
\end{abstract}

KEYWORDS: T cells; B cells; immunosenescense

\section{G Open Access}

Received: 31 March 2020

Accepted: 03 June 2020

Published: 11 June 2020

Copyright (c) 2020 by the author(s). Licensee Hapres, London, United Kingdom. This is an open access article distributed under the terms and conditions of $\underline{\text { Creative Commons Attribution }}$ 4.0 International License.

\section{ABBREVIATIONS}

acetyl-CoA carboxylase 1, ACC1; activated protein kinase, AMPK; central memory T, $\mathrm{T}_{\mathrm{CM}}$; dual-specific phosphatase 4, DUSP4; effector memory RA, $\mathrm{T}_{\mathrm{EMRA}}$; CMV, cytomegalovirus; cytotoxic T lymphocytes, CTLs; cytotoxic Tlymphocyte-associated protein, CTLA; dendritic cells, DCs; Epstein-Barr virus, EBV; estrogen-related receptor, ERR; extracellular signal-regulated kinase, ERK; follicular T helper, Tfh; forkhead box protein 01, FOXO1; glucose receptor, Glut; immunoglobulin transcription factor 1, E2A; interferon regulatory factor, IRF; interleukin, IL; interferon, IFN; liver X receptors, LXRs; mammalian target of rapamycin, mTOR; mitochondrial 
respiratory chain complex, MRC; nicotinamide adenine dinucleotide, NAD; nuclear factors of activated T cells, NFATs; nuclear respiratory factor 1 , NRF1; oxidative phosphorylation, OXPHOS; programmed cell death, PD; protein kinase B, Akt; phosphatidylinositol 3-kinase, PI3K; reactive oxygen species, ROS; recombination activating proteins, RAG; regulatory T cells, Tregs; sirtuins, SIRT; solute carrier family 13 member 5, SLC13A5; S6 kinase, S6K; sterol regulatory element binding transcription factor 2, SREBP2; TCR beta chain, TRB; T cell receptor, TCR; T helper cells type 1, Th1 cells; tricarboxylic acid, TCA; toll-like receptors, TLR; tumor necrosis factor, TNF

\section{INTRODUCTION}

In Western cultures, older adults comprise humans of or above 65 years of age. In other parts of the world like New Guinea, anyone above 50 is viewed as old. The United Nations makes a compromise and draws the line at 60. Older adults are not a homogeneous population. Some are remarkably fit while others are frail and suffer from multiple chronic diseases. Aging is defined as a gradual and irreversible decline in intrinsic physiological functions over time due to internal biological degeneration, which ultimately results in damages to molecules, cells, tissues and the organism as a whole [1]. Longevity, a parameter that can easily be measured, and aging, which is difficult to quantitate, have multiple underlaying causes. A number of theories have been formulated to explain the causes of aging. Burnett argued that cumulative genetic damage results in mammalian aging [2]. Orgel blamed aging on faulty protein synthesis [3], while Harman proposed damages caused by free-radicals [4]. Cerami hypothesized that aging is linked to aberrant post-translational glycosylation due to faults in glucose metabolism [5]. In 1957, William proposed the antagonistic pleiotropy hypothesis, which postulates that some genes encode traits that are beneficial during the reproductive stage of an individual but become detrimental upon aging [6]. The disposable soma theory of aging was formulated by Kirkwood, who hypothesized that somatic declines during aging is a trade-off for reproductive success in one's youth [7]. All of these theories are supported by some but not all data, stressing the complexity of aging. In the end, aging is caused by intrinsic and extrinsic factors that produce an imbalance of stress and stress-coping mechanisms, which gradually leads to irreversible damages.

Intrinsic factors include the genetic make-up and gene expression profiles of an individual [8]. Sirtuins (SIRT) are one set of genes that are being linked to aging. SIRTs control various aspects of metabolism and their activities increase under starvation, which may in part explain the link between caloric restriction and an extension of life span [9]. Other genes and gene products that affect aging include the mammalian target of rapamycin (mTOR) [10], autophagy-related genes (ATG), which are negatively regulated by mTOR complex 1 (mTORC1) [11], or the "I am not dead yet" (INDY) gene that encodes the citrate receptor solute carrier 
family 13 member 5 (SLC13A5) [12]. All of these longevity genes program proteins that affect metabolism, which points to metabolic imbalances as a hallmark of aging. Changes in metabolism such as declining mitochondrial functions increase the production of reactive oxygen species (ROS). Together with telomere shortening, they contribute to cellular senescence, a process that causes irreversible growth arrest of diploid cells [13] and deprives an aging body of the ability to repair damaged tissues [14]. Interestingly, cell senescence is linked to chronic inflammation [15], a common condition called inflammaging in older adults that contributes to increased morbidity and mortality. In addition, aging is affected by external forces such as life-styles, e.g., diet, exercise, smoking, oxidative stress and pollutants. Other factors, such as the socioeconomic status and level of education, influence the overall physical and mental fitness of individuals and therefore also have critical impacts on the biological aging process [16]. These factors induce epigenetic modifications and thereby changes in gene expression profiles in aged cells [17].

Aging affects key metabolic functions. In older adults, regulation of the energy balance between nutrient intake and expenditure becomes impaired, resulting in obesity or malnourishment [18]. The circadian rhythm is one of the basic forces that controls energy metabolism. The 24-h light-dark cycle dictates when we sleep or are active and when we eat or fast. Periods of anabolic metabolism during the active/feeding phase alternate with periods of catabolism during the sleep/fasting period. The circadian rhythm changes with age and circadian amplitude diminishes [19]. Furthermore, aging leads to alterations in glucose metabolism combined with reduced secretion and functions of insulin [20]. Lipid metabolism becomes unhinged with excess release of fatty acids from adipose tissues and a reduced rate of lipid catabolism [21]. Amino acid metabolism is relatively unaffected by age, although amino acid signaling through the mTOR pathway declines [22].

Aging has profound effects on the immune system's ability to mount adequate adaptive responses that protect against pathogens or eliminate transformed cells while preventing damaging autoimmune responses [23-26]. Lymphocytes in many ways are unique cells. They are replenished throughout life from bone marrow progenitors. They have to undergo selection to eliminate those that are self-reactive. They can migrate throughout the body, which exposes them to environments that vary in nutrients and oxygen. For example, peripheral blood is high in glucose while adipose tissue is high in fatty acids. Liver, particularly, has very high levels of glucose. Oxygen tension is high in blood and relatively low in bone marrow and some parts of lymph nodes. Once lymphocytes encounter a threat, they have to very rapidly transition from a quiescent stage that consumes minimal energy to an activated stage. This requires quick metabolic changes to allow for extensive cell proliferation and increased anabolic reactions to support cell divisions and effector 
functions. Aging is associated with a loss of metabolic flexibility, which ultimately leads to reductions in protective $\mathrm{T}$ and $\mathrm{B}$ cell responses and increases in pathological responses.

\section{T CELL METABOLISM}

T lymphocytes, the mediators of cellular immunity, arise in the bone marrow and migrate to and mature in the thymus. $\mathrm{T}$ cell maturation from committed progenitors involves the sequential rearrangement and expression of T cell receptor (TCR) genes, cell proliferation, peptide-major histocompatibility complex (MHC)-mediated positive and negative selection, and the acquisition of functional properties [27]. The two major subsets of matured $\mathrm{T}$ cells that leave the thymus and circulate in the periphery are $\mathrm{CD} 4^{+}$helper $\mathrm{T}$ lymphocytes and $\mathrm{CD} 8^{+} \mathrm{T}$ lymphocytes. Two major signals are provided by antigen presenting cells (APCs), especially dendritic cells (DCs), for T cell activation. The interaction of the TCR with peptide-MHC complex on antigen-presenting cells (APCs) provides "signal 1", while binding of costimulatory molecules such as CD28 on T cells to their ligands such as CD80 or CD86 on DCs provide "signal 2" [28]. Furthermore, pro-inflammatory cytokines provide "signal 3" and promote the differentiation of both $\mathrm{CD} 4^{+}$and $\mathrm{CD} 8^{+} \mathrm{T}$ cells [29]. Depending on the cytokine milieu of the microenvironment, $\mathrm{CD} 4^{+} \mathrm{T}$ cells can differentiate into different helper $\mathrm{T}$ cell lineages with unique functions, including $\mathrm{T}$ helper cells type 1 (Th1 cells), Th2 cells, Th9 cells, Th17 cells, follicular T helper (Tfh) cells, and $\mathrm{CD} 4^{+}$regulatory $\mathrm{T}$ cells (Tregs) [30]. In response to antigenic stimulation, helper $\mathrm{T}$ cells secrete cytokines, which promote their own proliferation and differentiation, and support activation of other immune cells such as B cells and DCs. With the help of cytokines such as IL-12 and type 1 interferon (IFN) [31], $\mathrm{CD}^{+} \mathrm{T}$ cells differentiate into functional cytotoxic $\mathrm{T}$ lymphocytes (CTLs), which are specialized to directly kill infected and transformed cells by granzyme and perforinmediated cell lysis [32]. In addition, CTLs secrete cytokines, mostly IFN- $\gamma$ and tumor necrosis factor (TNF), in order to induce inflammation and carry out their cytotoxic functions [33]. Following the clearance of foreign antigen and the collapse of the primary response, the majority of effector $\mathrm{T}$ cells undergoes apoptosis, while a small subset of them survives to become long-lived memory $\mathrm{T}$ cells [34]. However, with chronic antigen stimulation in the case of persistent infection and cancer, effector $\mathrm{T}$ cells become anergic or exhausted with progressive loss of proliferative capacity, impaired effector functions, and an altered transcriptional program [35]. Finally, a unique population of $\mathrm{CD}^{+} \mathrm{T}$ cells, named mucosalassociated invariant T (MAIT) cells, constitute a sizable proportion of $\mathrm{T}$ cells in human peripheral blood and different tissues [36]. MAIT cells are innate T cells that express semi-variant TCRs, called TRAV1-TRAJ33 in mice and TRAV1-2-TRAJ33/12/20 in humans [37]. They recognize metabolites of the riboflavin metabolism pathway, found in certain bacteria, that are presented by MHC-related molecule 1 (MR)1. MAIT cells exhibit an effector 
memory T (TEM) cell phenotype [38]. Upon stimulation through TCR ligation or by cytokines in the absence of exogenous antigens, MAIT cells respond rapidly by producing cytokines such as IFN- $\gamma$, TNF, and interleukin (IL)-17, and cytotoxic molecules granzyme B and perforin, therefore providing efficient protection against bacterial and viral infections [39].

Each of the $\mathrm{T}$ cell lineages show distinct metabolic profiles that play critical roles in their maintenance and in support of their specific functions [40]. Naive T cells circulate through secondary lymphoid tissues to perform immune surveillance. These resting $\mathrm{T}$ cells require a minimum amount of energy production and basal replacement biosynthesis to support their activities. They rely primarily on mitochondrial oxidative phosphorylation (OXPHOS) fueled by glucose-derived pyruvate, exogenous fatty acids and glutamine for triphosphate (ATP) production [41,42]. Upon antigen stimulation, $\mathrm{T}$ cells rapidly proliferate and commence effector functions. Activated T cells are characterized by their enhanced metabolic flexibility. They can use multiple nutrient sources to promote both their energy production and biomolecule synthesis activities [43]. However, compared to resting $\mathrm{T}$ cells, activated $\mathrm{T}$ cells prioritize anabolism with enhanced synthesis of lipid membranes, nucleic acids, and proteins over catabolism for ATP generation [44]. Activated T cells greatly increase their glucose uptake via glucose receptor (Glut)1 and potentially Glut4, which supports their upregulated glycolytic activity even in the presence of oxygen, a metabolic program named aerobic glycolysis [45-47]. Enhanced aerobic glycolysis of $\mathrm{T}$ lymphocytes is essential for their biosynthesis to support cell proliferation and functions. In addition, a portion of glucose enters the tricarboxylic acid (TCA) cycle to support ATP production. Glucose-derived acetyl-CoA is also converted into citrate for lipid synthesis [48]. Besides the contribution from glucose, catabolism of amino acids, such as glutamine, leucine and serine, are increased in activated $\mathrm{T}$ cells $[43,49]$. Glutamine is the most abundant amino acid in the circulation. In activated T cells, glutaminolysis is greatly enhanced. In this process glutamine is converted to a-ketoglutarate, which can be used either as an anaplerosis source to fuel the TCA cycle or as a metabolic intermediate for acetyl-CoA production and lipid synthesis [50,51]. Concomitantly, lipid oxidation is greatly reduced in activated T cells [52].

A number of transcriptional and posttranscriptional regulators as well as nuclear hormone receptors, i.e., cellular master regulator of cell cycle entry and proliferative metabolism (c-Myc), the phosphatidylinositol 3kinase (PI3K)/protein kinase B (Akt)/mTOR pathways, the estrogen-related receptor (ERR)a, and the liver $\mathrm{X}$ receptors (LXRs), have been shown to regulate $\mathrm{T}$ cell metabolism to support $\mathrm{T}$ cell activation and effector functions via distinct mechanisms [40]. c-Myc broadly promotes various facets of the metabolism in effector $\mathrm{T}$ cells including glucose and glutamine metabolism as well as mitochondrial biogenesis [53]. c-Myc 
drives expression of all of the glycolytic genes. It is also crucial for $\mathrm{T}$ cells to enhance glutaminolysis for ATP production and lipid and DNA synthesis [54]. The PI3K/Akt/mTOR pathway is activated in T cells during CD28mediated costimulation. The activity of this pathway is crucial for the differentiation, proliferation and metabolic reprograming of different subsets of $\mathrm{CD}^{+} \mathrm{T}$ cells and CTLs [55-59]. Akt promotes surface expression of both glucose transporter Glut1 and amino acid transporters [60,61]. It also enhances glycolysis by directly activating glycolytic enzymes [62]. In addition, Akt/mTORC1 via sterol regulatory element binding transcription factor 2 (SREBP2) activation enhances lipid synthesis while decreasing carnitine palmitoyltransferase (Cpt)1a-mediated lipid catabolism [63,64]. ERRa also plays a critical role in promoting glycolysis and glucose-fueled mitochondrial OXPHOS and ATP production, while LXR is a key regulator in T cells for lipid and cholesterol synthesis [65,66].

Different subsets of $\mathrm{CD}^{+}$and $\mathrm{CD} 8^{+} \mathrm{T}$ cells are metabolically distinct. Differentiation of Th1 and Th17 cells relies on mTORC1 activation and glycolysis [40,67]. Furthermore, hypoxia inducible factor-1a (HIF-1a) is selectively required for metabolic regulation in Th17 cells [68]. Activated Th2 cells also display high glycolytic activity and mTORC2 is essential for their differentiation and metabolic reprogramming [55]. Tfh cell differentiation requires increased activity of inducible $\mathrm{T}$ cell co-stimulator (ICOS)-dependent glucose metabolism, which relies on both mTORC1 and mTOCR2 activation [58]. In contrast, $\mathrm{CD}^{+}$Tregs show the lowest rate of glycolysis among all $\mathrm{CD}^{+} \mathrm{T}$ cell subsets. Instead, Tregs display high mitochondrial membrane potential and mainly rely on enhanced lipid oxidation for energy production [67]. The liver kinase B1 (LKB1) as a metabolic sensor has been implicated as a major factor for the cellular metabolism and energy homeostasis of Tregs [69]. Similar to Th1 and Th17 cells, mTORC1 activation and HIF-1a-dependent glucose metabolism are crucial for $\mathrm{CD}^{+} \mathrm{T}$ cell differentiation and their ability to produce IFN- $\gamma$ [70]. Specifically, resting MAIT cells, although possessing a distinct TEM cell profile, are metabolically quiescent and contain lower numbers of mitochondria compared to central memory $\mathrm{T}\left(\mathrm{T}_{\mathrm{CM}}\right)$ cells [38]. These cells show lower maximal respiratory potential and decreased expression of the OXPHOS genes. Resting MAIT cells exhibit similar levels of glycolytic rates compared naive or $\mathrm{T}_{\mathrm{CM}}$ cells, which are significantly lower compared to those of TEM cells. However, upon activation MAIT cells rapidly enhance their glucose uptake and glycolysis rate in a PI3K/Akt/mTORC1dependent manner, which is essential for their effector functions and production of IFN- $\gamma$ and granzyme B [38,71]. Furthermore, amino acid transport through Solute Carrier Family 7 Member 5 (SLC7A5) also contributes to mTOC1 activation in MAIT cells [39,72].

The presence of memory $\mathrm{T}$ cells is key in protecting the host against secondary infections. Memory $\mathrm{T}$ cells do not need high levels of biosynthesis but require efficient ATP production, primarily through lipid oxidation, to support their functions [73]. 5'-Adenosine monophosphate- 
activated protein kinase (AMPK) and TNF receptor-associated factor 6 (TRAF6) signaling are essential for the metabolic switch of memory T cells from a glycolytic state to an oxidative state, which is also important for memory T cell survival [74,75]. AMPK also inhibits the activity of acetylCoA carboxylase 1 (ACC1), a key enzyme for fatty acid synthesis [76].

Compared to naive $\mathrm{T}$ cells, which also rely on mitochondrial OXPHOS for energy generation, memory $\mathrm{T}$ cells contain elongated and fused mitochondria that have higher mass and spare respiratory capacity (SRC) [44,77]. SRC in memory $\mathrm{T}$ cells but not naive $\mathrm{T}$ cells mainly depends on fatty acid oxidation. Two of the major circulating memory $\mathrm{T}$ cell subsets are $\mathrm{T}_{\mathrm{EM}}$ and $\mathrm{T}_{\mathrm{CM}}$ cells [78]. $\mathrm{CD} 4^{+} \mathrm{T}_{\mathrm{CM}}$ and $\mathrm{T}_{\mathrm{EM}}$ cells show comparable frequencies in human blood, lymph nodes, and various peripheral tissues, while $\mathrm{CD}^{+} \mathrm{T}_{\mathrm{CM}}$ cells represent a much smaller population of $\mathrm{CD} 8^{+} \mathrm{T}$ cells in various compartments compared to $\mathrm{CD} 8^{+} \mathrm{T}_{\mathrm{EM}}$ cells [79]. However, with their superb proliferation capacity, $\mathrm{T}_{\mathrm{CM}}$ cells can replenish other memory $\mathrm{T}$ cell subsets, including $\mathrm{T}_{\mathrm{EM}}$ cells, and therefore play an essential role in providing effective long-term memory responses and immunosurveillance in human peripheral tissues [80]. Sustained HIF1a activity and high glycolytic rates promote the differentiation of $\mathrm{T}_{\mathrm{EM}}$ cells, while $\mathrm{T}_{\mathrm{CM}}$ cells show greater stem cell-like and self-renewal capacity with higher mitochondrial respiratory capacity [81,82]. In tissues, there is another type of memory $\mathrm{T}$ cell named tissue-resident memory $\mathrm{T}\left(\mathrm{T}_{\mathrm{RM}}\right)$ cell [83]. $\mathrm{T}_{\mathrm{RM}}$ cells exhibit long-term persistence in tissues and provide rapid host protection. Recent studies show that TRM cells can actually re-join the circulation pool, and exhibit the potential to differentiate into $\mathrm{T}_{\mathrm{EM}}, \mathrm{T}_{\mathrm{CM}}$, and $\mathrm{T}_{\mathrm{RM}}$ cells upon recall [84]. While circulating memory $\mathrm{T}$ cells preferentially use glucose for de novo fatty acid synthesis to fuel fatty acid oxidation, $\mathrm{T}_{\mathrm{RM}}$ cells mainly oxidize exogenous fatty acids taken up by fatty acid-binding protein (FABP)4 and FABP5 for energy production to maintain their functions [85]. Upon recognizing their cognate antigen, memory $\mathrm{T}$ cells have the unique ability to rapidly proliferate and exert effector functions. This rapid recall response of memory $\mathrm{T}$ cells is mainly supported by mTORC2-Akt mediated increases in glycolytic activity [86]. In addition, it has been shown that serum acetate serves as an important regulator of memory $\mathrm{T}$ cell glycolysis [87]. Serum acetate levels rapidly increase following an acute infection and the concomitant shift towards systemic catabolism. Acetate is converted to acetyl-CoA by the acetyl-CoA synthetases (ACSS) in memory T cells, which is used for glyceraldehyde 3phosphate dehydrogenase (GAPDH) acetylation. Acetylation of GAPDH increases its activity and glycolytic rates in memory $\mathrm{T}$ cells and promotes their secretion of IFN- $\gamma$ [87].

In the case of chronic stimulation with self-antigens, tumor antigens or during chronic infections, T cells may become anergic or exhausted. Either state is characterized by $\mathrm{T}$ cell hyporesponsiveness with loss of proliferative potential, cytokine production, and cytotoxic functions [88,89]. Metabolism is a key factor in modulating $\mathrm{T}$ cell anergy and 
exhaustion. Limiting glucose metabolism during $\mathrm{T}$ cell activation will make the $\mathrm{T}$ cells unable to fully engage mTOCR1 activation and directly drives $\mathrm{T}$ cell anergy [88]. Our study, together with other works, demonstrates that exhausted $\mathrm{T}$ cells reduce glycolytic rates and prefer to use mitochondrial OXPHOS for energy production [90,91]. Ligation of coinhibitory ligands, i.e., programmed cell death (PD)-1 and cytotoxic Tlymphocyte-associated protein (CTLA)-4, inhibits PI3K/Akt/mTORmediated glucose metabolism [92,93]. PD-1 ligation further facilitates the metabolic switch of $\mathrm{T}$ cells towards fatty acid oxidation [94]. As $\mathrm{T}$ cell exhaustion usually occurs in an environment depleted of glucose due to infection or tumor growth [95,96], these metabolic shifts are essential for $\mathrm{T}$ cells to at least partially preserve their effector functions.

\section{IMPACT OF AGING ON T CELL METABOLISM}

The $\mathrm{T}$ cell system faces numerous antigen challenges and adapts to various microenvironment throughout life, leading to a completely reformed immune system in older adults (Figure 1). T cell-mediated immune responses are increasingly compromised in aged individuals, which worsens complications from infections and dampens responses to vaccination [97,98]. Many factors, including genomic instability, loss of proteostasis, and metabolic dysfunction all contribute to age-related cellular dysfunctions [99,100]. This is especially the case for T cells, which need to constantly respond to new or chronic infections and malignancies, maintain a diverse $\mathrm{T}$ cell repertoire and a pool of memory $\mathrm{T}$ cells.

While thymic involution greatly contributes to loss of $\mathrm{T}$ cell immunity in aged mice, in human adults the thymus has limited contribution to $\mathrm{T}$ cell generation [101,102]. It accounts for about $16 \%$ of total T cell numbers in young adults and less than $1 \%$ in older adults [102,103]. Instead, naive $\mathrm{CD}^{+}$and $\mathrm{CD}^{+} \mathrm{T}$ cells in humans are largely maintained through homeostatic proliferation in the periphery with daily turnover rates of about $0.03-0.04 \%$ [103]. Both the size and composition of the naive T cells, i.e., the diversity of their TCR, enable immune responses to diverse antigens and are critical to preserve $\mathrm{T}$ cell immunity. In healthy older individuals, naive $\mathrm{CD}^{+} \mathrm{T}$ cell numbers in the periphery stay stable. In contrast, circulating naive $\mathrm{CD} 8^{+} \mathrm{T}$ cells are more susceptible to aging and their numbers decline with age [104,105]. The low-affinity TCR engagement with self-peptide/MHC complex and the higher sensitivity of naive $\mathrm{CD} 4^{+} \mathrm{T}$ to IL- 2 in older adults account for their better maintenance in peripheral tissues $[106,107]$. In contrast, naive $\mathrm{CD} 8^{+} \mathrm{T}$ cells do not rely on IL-2 for their peripheral maintenance. Instead, IL-2 drives the differentiation of naive $\mathrm{CD}^{+} \mathrm{T}$ cells into memory cells, which could partially explain the more pronounced decline of the naive $\mathrm{CD}^{+} \mathrm{T}$ cell compartment [108]. Indeed, aging is associated with a shift of naive $\mathrm{CD} 8^{+}$ T cells towards CD $8^{+}$TEM and TCM cell subsets [109]. Both naive $\mathrm{CD} 4^{+}$and $\mathrm{CD}^{+} \mathrm{T}$ cells have an estimated 50 to 100 million unique TCR beta chain (TRB) gene sequences [110]. It decreases around 2-5 folds during aging in 
healthy older people, still leaving a large $\mathrm{T}$ cell repertoire that can respond to various antigenic challenges [110]. The modest loss in TCR sequence diversity with age is unlikely to affect $\mathrm{T}$ cell functions. However, chronic inflammation develops with age due to chronic infection and increased adiposity, increasing levels of interleukin (IL)-6, TNF, IFN, and IL-1 $\beta$ in the $\mathrm{T}$ cells' environment [111-113]. TNF is known to reduce costimulatory molecule CD28 expression on naive T cells [114]. In addition, the proinflammatory cytokine milieu leads to chronic PI3K/Akt/mTOR pathway activation and increases basal Glut1 expression and glycolytic rates in naive $T$ cells $[115,116]$. The enhanced basal activation of signaling pathways and metabolism in naive $\mathrm{T}$ cells, together with their cumulative replicative history due to homeostatic proliferation drive the partial differentiation and dysfunction of naive T cells in older adults [108]. As a consequence, activation of $\mathrm{T}$ cells as well as their proliferative potential and cytotoxic functions are impaired in the aged adults, especially for naive $\mathrm{CD}^{+} \mathrm{T}$ cells $[115,117,118]$. The increased concentrations of inflammatory cytokines in the frail older individuals could also lower the responsiveness of $\mathrm{T}$ cells to cytokines and reduce $\mathrm{T}$ cell compartment size and repertoire diversity [119,120]. Although the basal metabolic rates of MAIT cells are similar as those of naive T cells, MAIT cell numbers decline significantly in older adults [121,122]. Paired TCRa $\beta$ analysis of MAIT cells revealed their striking TCR repertoire diversity, which is higher than the TCR repertoire diversity of viral antigen-specific $\mathrm{CD} 8^{+} \mathrm{T}$ cells. Similar to naive T cells, MAIT cells in older adults show large clonal expansion and narrower TCR repertories compared to their young adult compartments [71]. Studies by Loh et al. show that the upregulated basal inflammation in older adults contributes to the hyporesponsiveness of aged MAIT cells to inflammation-driven stimulation [71]. However, the magnitude of antimicrobial MR1-dependent response remains as high as those of younger adults, suggesting the potential of MAIT cells in older adults to provide immune protection.

Furthermore, age-related alterations in metabolism directly affects naive $\mathrm{CD}^{+} \mathrm{T}$ cell differentiation. Both obese patients and older adults show an increase in the deposition of fat around visceral organs, which contributes to insulin resistance and enhances the level of circulating insulin [123]. Insulin signaling plays an important role for $\mathrm{T}$ cell differentiation, which could work through the insulin receptor and insulin-like growth factor-1 receptor (IGF-1R) expressed on $\mathrm{CD} 4^{+} \mathrm{T}$ cells to modulate the PI3K/Akt/mTOR pathway activity in these cells [124]. It has been shown that the high amounts of insulin in obese patients and older adults promotes the PI3K/Akt activity in $\mathrm{CD} 4^{+} \mathrm{T}$ cells, which reduces the number of natural Tregs and also dampens IL-10 production and immunosuppression by Tregs [125]. Instead, numbers of adaptive Tregs in visceral adipose tissues increase in these patients and older adults [126]. The enhanced PI3K/Akt activity together with elevated proinflammatory cytokine levels in older adults also promote the formation of both Th1 and 
Th2 cells [127,128]. They may also contribute to the increased levels of activated $\mathrm{CD} 4^{+} \mathrm{T}$ cells and cytotoxic $\mathrm{CD} 4^{+} \mathrm{T}$ cells that have been observed in both older adults and old mice [124,129]. An enhanced ratio of Th1 to Th2 cells is also associated with aging [128], which could be due to preferential activation of mTORC1 over mTORC2 by insulin signaling in $\mathrm{CD} 4^{+} \mathrm{T}$ cells that facilitates Th1 cell polarization [130]. Besides the elevated insulin signaling, another hormone associates with both obesity and aging, leptin, could promote the survival of Th1/Th17 cells while inhibiting the proliferation of Tregs, therefore enhancing the susceptibility of older adults to autoimmune diseases [131]. Moreover, $\mathrm{T}$ cells in older adults show increased accumulation of free radicals and experience higher oxidative stress [132]. The free radical oxidation of tryptophan generates kynurenine [133], which increases during aging and could drive $\mathrm{CD} 4^{+} \mathrm{T}$ cell differentiation towards Th17 cells and promotes autoimmunity [134].

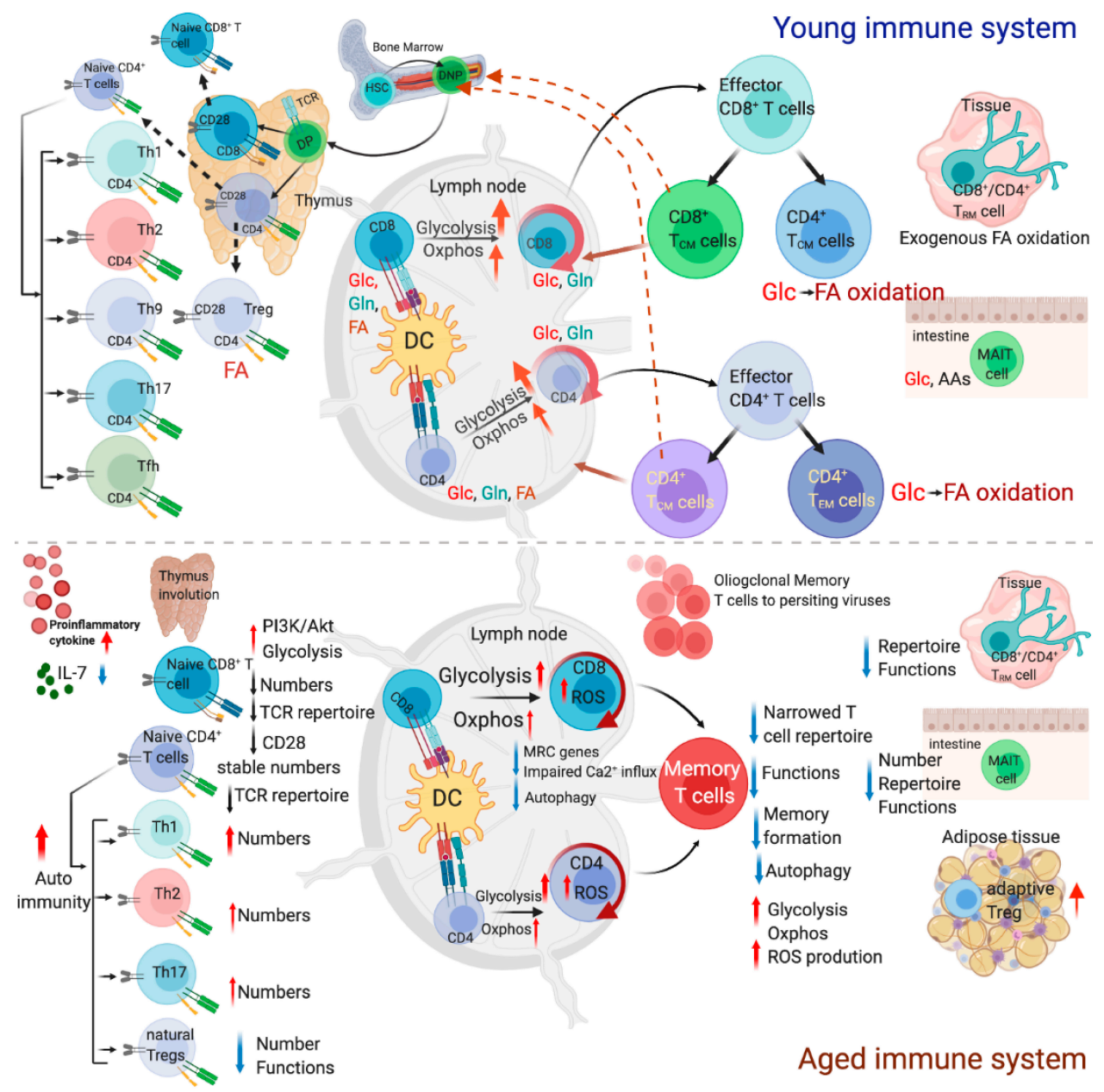

Figure 1. Impact of aging on $T$ cell differentiation, function and metabolism. The differentiation of both $\mathrm{CD}^{+}$and $\mathrm{CD} 4^{+} \mathrm{T}$ cells as well as their metabolism in the young (upper panel) and older adults (lower panel). The changes of $T_{R M}$ cells, MAIT cells, as well as adaptive Tregs in adipose tissue in the aged environment are also shown. HSC: hematopoietic stem cells; DNP: double negative precursors; DP: double positive; Glc: glucose; Gln: glutamine; FA: fatty acids; AA: amino acids; MRC: mitochondrial respiratory chain complex. *Created with Biorender.com (https://biorender.com/). 
Compared to naive $\mathrm{T}$ cells, memory $\mathrm{T}$ cells exhibit more dynamic homeostatic turnover rates of about $0.6 \%$ per day [135]. The overall TCR sequence diversity of memory $\mathrm{T}$ cells remains stable during aging [110]. However, latent viral infections with herpes viruses such as cytomegalovirus (CMV) or Epstein-Barr virus (EBV) are common in humans and have major impacts on the peripheral blood memory $\mathrm{T}$ cell composition in older adults [136,137]. Each episode of virus infection and/or reactivation could lead to significant disturbances due to clonal expansion of antigen-specific $\mathrm{T}$ cells. Memory $\mathrm{T}$ cell inflation, i.e., the formation and maintenance of effector memory $\mathrm{T}$ cell clones specific towards a number of CMV antigens, is common in older adults and has been viewed as beneficial for controlling viral latency without obvious adverse effects on general $\mathrm{T}$ cell immunity [138-140]. CMV infection in older adults also contributes to the expansion of terminally differentiated effector memory $\mathrm{T}$ cells that re-expresses CD45RA (TEMRA), especially in the $\mathrm{CD}^{+} \mathrm{T}$ cell compartment [109,141]. CD8 ${ }^{+}$TEMRA cells are highly oligoclonal, with single clone frequencies up to $1 \%$ in the peripheral blood and therefore promote contraction in TCR repertoire breadth [142]. TEMRA cells show features of cell senescence and metabolic dysfunctions, with reduced proliferative potential and impaired capacity to control viral infection [143,144]. In addition, in older individuals, repeated antigen stimulation by virus infections and/or reactivations could result in narrowing of the antigen-specific memory $\mathrm{T}$ cell repertoire and even loss of memory $\mathrm{T}$ cells; both dampen the capacity of $\mathrm{T}$ cell-mediated virus control and cross-protection in older adults [145,146].

$\mathrm{T}$ cell metabolism plays a tremendous role in regulating $\mathrm{T}$ cell growth, differentiation, and functions. Aging affects $\mathrm{T}$ cell metabolism via multitudes of mechanisms, which directly or indirectly contribute to T cell dysfunctions in older adults [99]. For example, genome instability caused by DNA point mutations, insertions and deletion, and chromosomal rearrangements is a hallmark of aging [100]. It could affect $T$ cell metabolism through (1) damage to mitochondria DNA or mutations in metabolic genes [147,148], (2) impaired epigenetic regulations that lead to altered metabolic gene expression [149], (3) telomere erosion-induced repression of peroxisome proliferation-activated receptor gamma, coactivator 1 alpha and beta (PGC1 $\alpha$ and PGC1 $\beta$ ), which leads to impaired mitochondrial biogenesis and functions, reduced gluconeogenesis and oxidative defense [150]. Additionally, various external and endogenous stresses accumulate in T cells with aging, which lead to the dysregulation of protein homeostasis and proteome integrity [151]. Proteome deterioration also contributes to impaired $\mathrm{T}$ cell metabolism via different mechanisms [152-154], such as (1) accumulated damage and defects in post-translational modification leading to dysfunctions of metabolic enzymes in T cells, (2) deficiency in recycled biomolecules that could be used for catabolism to produce energy or as building blocks for other macromolecules, (3) a loss of mitophagy, i.e., the degradation of defective 
mitochondria by autophagy. All these challenges could result in impaired mitochondria functions and enhanced ROS production, as well as defects in metabolic activities. Indeed, it has been reported that $\mathrm{T}$ cells in older individuals show a series of mitochondrial and metabolic deficits [155].

Aging can either directly affect the metabolism of different $\mathrm{T}$ cell subsets, or indirectly dampen $\mathrm{T}$ cell metabolism through modulating a number of signaling pathways. For example, a recent study showed that circulating naive and central memory $\mathrm{CD}^{+} \mathrm{T}$ cells in older adults lost expression of mitochondrial respiratory chain complex (MRC) genes, which results in an increase in mitochondrial mass but a reduction in mitochondrial OXPHOS capacity in aged T cells [155]. Transcription factor nuclear respiratory factor 1 (NRF1) has been shown to be essential for regulating mitochondrial gene expression [156]. It turns out that the defects in MRC gene expression in aged T cells are due to a failure of NRF1 to keep MRC gene promoters open. Along the same lines, studies with young and aged mice show that aged naive $\mathrm{CD} 4^{+} \mathrm{T}$ cells develop smaller mitochondria with reduced respiratory capacity upon activation. This is largely due to a deficiency in the induction of enzymes in the mitochondrial one-carbon metabolism pathway, which is important for redox homeostasis and mitochondrial protein synthesis to support OXPHOS [157]. IL-7, a cytokine essential for the homeostatic proliferation of naive T cells, declines with aging [158]. IL-7 reduction, together with dysregulated lymph nodes in older adults [159], are likely to impair the metabolic fitness of naive $\mathrm{T}$ cells. Upon naive $\mathrm{T}$ cell activation, TCR engagement and costimulatory signaling drive calcium $\left(\mathrm{Ca}^{2+}\right)$ influx by inducing its release from the endoplasmic reticulum (ER) and extracellular spaces $[160,161]$. The rise in intracellular $\mathrm{Ca}^{2+}$ serves as a critical signal to mediate activation of nuclear factors of activated T cells (NFATs) and their translocation to the nucleus, where they regulate expression of various genes associated with $\mathrm{T}$ cell activation, metabolism and differentiation [162]. However, in older adults the ion homeostasis is often dysregulated, leading to impaired $\mathrm{Ca}^{2+}$ flux [163]. The age-related damage to mitochondria may also reduce their ability to buffer local $\mathrm{Ca}^{2+}$ concentrations, leading to impaired NFAT signaling. As NFATs directly regulate the expression of "metabolic master regulators", i.e., IFN regulatory factor (IRF)4, HIF-1a, and c-Myc, reduced activity of NFATs in aged $\mathrm{T}$ cells is expected to dampen the rates of $\mathrm{T}$ cell glycolysis and mitochondrial respiration, impair $\mathrm{T}$ cell activation and effector $\mathrm{T}$ cell functions [164]. How aging affects the metabolism of MAIT cells has not yet been studied. However, obesity that similar to aging leads to hyperinflammation and altered metabolism has been shown to dampen the glycolytic metabolism, mTORC1 signaling, and amino acid transport in MAIT cells [39]. It is tempting to speculate that age-associated defects negatively affect MAIT cell metabolism at both their resting and activated states in older adults, which contribute to the reduced frequencies of MAIT cells at baseline and their impaired functions upon antigen stimulation. 
The formation and functions of memory $\mathrm{T}$ cells are impaired in older adults, which can be attributed to many age-related metabolic defects. Autophagy, as a crucial process to remove toxic products and damaged cells, begins to fail with aging [165], which has been suggested to negatively affect metabolic switches during $\mathrm{T}$ cell activation and prevent memory $\mathrm{T}$ cell formation [166]. Puleston et al. showed that autophagydeficient antigen-specific CD8 ${ }^{+} \mathrm{T}$ cells display enhanced Glut1 expression, mitochondria mass and oxidative stress as well as increased apoptotic rates. These cells fail to downregulate Glut1 and are unable to switch from glycolysis to mitochondrial OXPHOS, which is important for the survival of memory $\mathrm{T}$ cells. The defects in autophagy in memory $\mathrm{T}$ cells also dramatically impairs their recall responses. After activation, aged $\mathrm{CD} 8^{+} \mathrm{T}$ cells are also twice more likely than their younger counterparts to express CD39 [167]. CD39 works as a rate-liming ATPase by cleaving secreted ATP to generate adenosine [168]. Adenosine signals via the adenosine A2AR receptor to induce immune suppression and promote effector $\mathrm{T}$ cell apoptosis after antigen encounter, which impairs the memory $\mathrm{T}$ cell formation [169]. In addition, the metabolic master regulator AMPK is hyperactivated in aged T cells, potentially as a response to energy stress or nutrient sensing restrictions, which leads to increased basal mitochondrial biogenesis [170]. AMPK also induces expression of the nuclear dual-specific phosphatase 4 (DUSP4) in aged CD4 $4^{+}$memory T cells, which by terminating nuclear extracellular signal-regulated kinase (ERK) activity impairs their proliferation and helper functions to support B cell differentiation [171]. Furthermore, cellular stress in aged memory T cells leads to hyperactivation of the sestrin-MAPK signaling cascade, which increases the basal glycolytic rates in memory $\mathrm{T}$ cells and impairs their proliferation and production of cytokines [144,170].

The metabolic profiles of several memory $\mathrm{T}$ cell subsets in older adults have been studied. In general, aging leads to moderately increased Glut1 expression and PI3K/Akt/mTOR/ ribosomal protein S6 kinase (S6K) pathway activation in resting memory $\mathrm{T}$ cells, promoting their glycolysis rate [172]. In activated memory $\mathrm{T}$ cells, aging actually slightly increases their mitochondrial OXPHOS rates although mitochondria ROS production is much higher [173]. Terminally differentiated $\mathrm{CD} 8^{+} \mathrm{CD} 28^{-}$memory $\mathrm{T}$ cells and TEMRA cells accumulate in older adults $[174,175]$. Human CD8 ${ }^{+}$CD28 $\mathrm{T}$ cells show markedly reduced expression of SIRT1, which as a nicotinamide adenine dinucleotide (NAD) ${ }^{+}$-dependent protein deacetylase regulates many cellular processes linked to metabolism and longevity [176]. The transcriptional factor forkhead box protein 01 (FOXO1) as a SIRT1 target is proteasomally degraded in SIRT1-deficient CD8 ${ }^{+} \mathrm{CD} 28^{-} \mathrm{T}$ cells, which promotes their glycolytic rates and increased their granzyme B production. Finally, human TEMRA cells enriched in older adults show age-associated increases in glycolysis. These cells contain low numbers of mitochondria, and therefore exhibit impaired metabolic rates upon $\mathrm{T}$ cell 
activation but instead produce disproportionally higher levels of ROS and encounter increased oxidative stress [144,177].

Currently, it remains unclear how these aging-induced metabolic changes in T cells affect their survival and functions in older adults, which is a critical question to be investigated. It is tempting to speculate that some of the metabolic alterations observed in aged T cells allow them to adapt to the changing microenvironment in older adults, which would serve to either prolong their survival under resting conditions, or partially preserve their effector functions upon activation. It is also important to point out that how much does aging affect $\mathrm{T}$ cell metabolism and effector functions depend on an individual's metabolic rates. A number of studies suggest that reducing metabolic rates by caloric restriction or mTOR inhibition could alleviate age-related $\mathrm{T}$ cell dysfunction and increase lifespan [178-180].

\section{B CELL METABOLISM}

The main job of a B cell is to produce antibodies that neutralize a pathogen or with the help of other immune mediators, such as complement or natural killer cells, directly kill the pathogen or the cells it infects [181]. B cells are derived from hematopoietic stem cells in the bone marrow. Following rearrangement of their immunoglobulin (Ig) heavy chain, pro-B cells differentiate first into large and then small pre-B cells, which is promoted by recombination activating proteins (RAG) 1 and 2 and immunoglobulin transcription factor 1 (E2A) [182,183]. Ig light chain gene rearrangements take place later during the pre-B cell stage. During these transitions B cells proliferate in response to IL-7 and increase glucose uptake and mitochondrial mass, a process that is regulated by the inner mitochondrial membrane protein swiprosin [184]. Pre-B cells then leave the bone marrow as transitional B cells that undergo negative selection to eliminate those with potent activity to self-antigen [185]. Cells are subsequently positively selected based on low-level B cell receptor (BCR) interactions, which allow them to successfully compete for binding to Bcell-activating factor (BAFF), a scarce and thereby limiting survival factor [186]. After selection B cells home to lymphatic tissues, where they mature either into follicular B2-B cells or marginal zone (MZ) B cells. This choice depends on BCR signaling strength during B cell maturation [187]. A third subset, B1-B cells, develops early during fetal life [188]. B1-B cells have distinct Ig receptors that lack the diversity of B2-BCRs and they are able to self-renew. B1-B cells home to the pleural and peritoneal cavities, get activated rapidly at these sites and produce IgM and IgA without T cell help [189]. MZ B cells are found in the marginal zones of lymphatic tissue, where they play a role in antigen transport and presentation [190]. Their activation into IgM- or IgG3-producing antibody-secreting cells (ASCs) is also independent of $\mathrm{T}$ cell help. B2-B cells, the most common type of B cells from here on referred to just as B cells, circulate and home to B cell follicles within lymph nodes. Once antigen binds to surface-expressed monomeric 
Ig, which serves as the BCR, B cells in the presence of $\mathrm{T}$ cell help become activated. This step involves signaling through the BCR and its co-receptor CD19, a key B cell marker [191]. PI3K becomes activated and in turn induces AKT and the mTOR pathways [192]. As a results B cells start to proliferate and then form germinal centers, where they continue to cycle. Germinal centers separate into light and dark zones within a few days [193]. Within the dark zones B cells proliferate and their Ig genes undergo class-switching and somatic hypermutations to optimize antibody functions and affinity to their cognate antigens. They then move to the light zones, which contain antigen carrying-follicular dendritic cells (FDCs) and Tfh cells [193]. B cells stop to proliferate within the light zones where they undergo positive selection by interacting with their antigen presented by FDCs and receiving help from surrounding Tfh cells [194]. B cells that do not encounter their antigen and receive $T$ cell help die. Selected B can then either move back into the dark zones for additional rounds of proliferation and somatic hypermutation or differentiate into short- or long-lived antibody-producing plasma cells. Alternatively, they can become memory B cells. B cell fate decisions are driven by a number of factors, i.e., the availability of T cell help and cytokines [195,196], Tolllike receptors (TLR) ligation [197], and the signaling strength of the BCR. One key transcription factor governing B cell fate decision is B-cell lymphoma 6 protein (BCL6), which is essential for germinal center formation, B cell proliferation, Ig gene rearrangement, and tolerance of DNA breaks. BCL6, induced by interferon regulatory factor (IRF)8 together with BTB domain and $\mathrm{CNC}$ homolog (BACH)2 inhibits plasma cell differentiation through repression of beta-interferon gene positiveregulatory domain I binding factor (BLIMP1) encoded by PR/SET domain 1 (PRDM1) [198]. IRF4 downregulates BCL6 and thereby allows for expression of BLIMP1, which in turn facilitates B cell differentiation towards plasma cells by promoting expression of X-box binding protein (XBP)1 [199,200]. XBP1 prompts remodeling of the ER, activates autophagy and the unfolded protein response and initiates the mTOR pathway to increase protein synthesis.

B cell differentiation is characterized by repeated bursts of proliferation followed by periods of relative quiescence and each stage poses its unique bioenergetic demands. During development in the bone marrow pro-B cells proliferate when transitioning towards pre-B cells. They increase energy production through glycolysis and mitochondrial OXPHOS, which are fueled by glucose and fatty acids [201]. Small pre-B cells, transitional B cells and naïve B cells are relatively quiescent and their modest energy demands are met by OXPHOS. Resting B cells require less energy compared to resting $T$ cells although they produce on a per cell basis more proteins. This is especially pronounced for B cells that are involved in antigen presentation and transport such as MZ B cells [202].

Upon activation B cells upregulate MHC class II molecules and costimulators such as CD80 and CD86 to present antigen to CD $4^{+} \mathrm{T}$ cells [203]. 
B cells rapidly increase energy and biomass production through the PI3K pathway to allow for cell cycling, which initially takes place within B cell follicles [192,204]. B cells increase uptake of nutrients such as glucose and glutamine. Some have reported that the consumed glucose augments glycolytic energy production [205-207]. Others have shown using metabolic tracing that glucose cycles through the glycolytic pathway but is then used mainly for biosynthesis of ribonucleotides and lipids, the latter to support synthesis of cell membranes [208]. Activated B cells also increase oxygen consumption and energy production through the TCA cycle and OXPHOS, which is largely fueled by glutamine and is accompanied by mitochondrial remodeling. Increased mitochondrial ATP generation augments ROS production. ROS plays a role in B cell fate decisions by driving class switch reactions and thereby delaying $B$ cell differentiation into plasma cells [209].

Throughout germinal center reactions, the B cells' demand for energy and biomass constantly shift. B cells undergo bursts of energy consumption during proliferation in the dark zone, followed by the more passive positive selection in the light zone. This requires rapid metabolic adjustments, which may in part be driven by FOXO1 that is highly expressed in dark zone B cells and PI3K that shows increased activity once B cells enter the light zone [192,210]. It is suggested that higher activity of FOXO1 in proliferating cells is needed to modulate chemokine receptor expression and class switch reactions. Its role in modifying metabolism of dark zone B cells, which presumably depends on mitochondrial energy production to support their proliferation and class-switch reactions, remains unknown. The heightened activity of PI3K in light zone B cells inhibits FOXO1 activity through activation of AKT. The light zone is relatively hypoxic [211]. Hypoxia increases the activity of HIF-1a forcing B cells to rely more on glycolysis for energy production [211-213]. This metabolic adjustment decreases mitochondrial OXPHOS and ROS production, which in turn promotes plasma cell development. If B cells are triggered only by $\mathrm{BCR}$ engagement, their mitochondria become functionally impaired. These B cells are no longer able to maintain the cells' $\mathrm{Ca}^{2+}$ homeostasis and ROS levels increase, which leads to enhanced cell death. A second signal provided by T helper cells or TLR9 ligation is required within about 9 hours after BCR signaling to restore mitochondrial functions [214].

After germinal center maturation, B cells that differentiate into memory cells migrate mainly to the bone marrow where they can survive for very long periods of time without $\mathrm{T}$ cell help or interactions with their cognate antigen [215]. They are quiescent at this stage and use OXPHOS for energy production. Unlike naïve B cells, memory B cells are poised for rapid reactivation, which heightens their energy consumption. Autophagy is dispensable for the formation of memory B cells while it is essential for memory B cell survival [216]. Autophagy could be important to maintain mitochondrial homeostasis by removing those that become unfit. It may 
also help B cells to degrade lipid droplets by lipophagy to release triglycerides for fatty acid $\beta$-oxidation, generating acetyl-CoA to fuel the TCA cycle [217].

Plasma cells are terminally differentiated with reduced CD19 expression. Their sole purpose is to produce and secrete vast amounts of antibodies. Plasma cells synthesize thousands of complex molecules per second, then fold them correctly and transfer them out of the cells. These activities require large amounts of amino acids for protein synthesis and sugars for energy production and post-translational glycosylation [218]. Prdm1, also known as BLIMP1, drives plasma cell differentiation. This transcription factor increases expression of transporters of amino acids. The increased uptake of amino acids, such as leucine and arginine, in turn activates mTORC1, which increases protein synthesis. Amino acids are not only used for anabolic reactions but are also catabolized for energy production. Intestinal B cells take up short fatty acids produced by microbiota to fuel energy production [219]. The accumulation of large amounts of antibodies in the secretory pathway causes an ER stress response. The activity of autophagy pathways increases to remove misfolded proteins and ER components that are no longer needed [220]. It has also been shown that long-lived but not short-lived plasma cells rely on energy production through the glucose-fueled TCA cycle and OXPHOS [218].

Resting B1-B cells are metabolically more active than B2-B cells. They show elevated levels of glucose uptake, glycolysis and OXPHOS. Upon activation B1-B cells unlike B2-B cells depend on glucose as a nutrient. Peritoneal cavities, where B1-B cells reside, are rich in fatty acids and accordingly B1-B unlike B2-B cells take up substantial amounts of lipids and store them in the form of triglycerides in lipid droplets. Autophagy, which regulates lipid metabolism [221], is increased in B1-B cells and is essential for lipid uptake and the cells' ability to self-renew [222]. ROS can damage cells for example by causing membrane lipid peroxidation, which is prevented by increased activity of the glutathione peroxidase 4 (GPX4), a ROS scavenger. As GPX4 increases are seen in B1- and MZ B cells but not in B2-B cells, it suggests that the B1-B cells' higher baseline metabolism, which may allow them to respond more rapidly to an incoming threat, might be shared by MZ B cells [223].

\section{EFFECTS OF AGING ON B CELL METABOLISM}

B cell responses to vaccines or pathogens decline in the aged, which renders them highly susceptible to infectious diseases. This is best exemplified by influenza viruses, which cause death mainly in older adults. Annual influenza vaccines provide some protection to younger people, but commonly fail to induce sufficiently potent neutralizing antibody responses in older adults [224,225]. Immunosenescence affects multiple aspects of B cell responses. Output of immature B cells from bone marrow declines [226]. Hematopoietic stem cells become more prone to 
differentiate into myeloid cells due to epigenetic changes [227] as well as plasma cell-derived alterations in the bone marrow's cytokine milieu [228]. The activity of transcription factors that assist in the transition of B cell progenitors to pro- and then pre-B cells, such as E2A and RAG, decline with age, which together with a reduced responsiveness to IL-7 further hampers B cell development [229,230]. Reduced output of B cells from bone marrow may lead to a relaxation of negative and positive selection due to lowered competition for BAFF, which in turn may allow for survival of auto-reactive B cells. It also leads to a proportional increase of B1-B cells, the source of so-called "natural" low affinity IgM antibodies [231], although absolute numbers of B1-B cells in the periphery decline with age [232]. Positioned in the inner wall of the subcapsular sinus of lymph nodes, MZ B cells are specialized in capturing antigens and transporting them to FDCs in B lymphoid follicles. However, their antigen transfer capacity also becomes impaired with age [233]. Clonal diversity of naïve B cells declines with age. This may be caused by intrinsic defects of progenitors, or reduced output of B cells from bone marrow [234]. Formation of germinal centers becomes impaired and Thelper cell functions decrease as well in older adults [235-237]. Furthermore, in older individuals, class-switching and affinity maturation by somatic hypermutations slow down resulting in lower quality antibodies [238].

Changes in metabolic fitness contribute to the impaired B cell responses in aging adults (Figure 2). Admittedly, very few studies thus far assessed pathways of energy and biomass production during B cell activation and differentiation in older humans or animals. However, our knowledge of general metabolic changes in older adults, combined with the above described metabolic adjustments that are needed for B cell development and activities, allow us to make some assumptions that, notwithstanding, will have to be addressed experimentally. The PI3K-mTOR pathway plays a key role in B cell activation [239]. In B cells this pathway is induced by signaling through the BCR-CD19 complex or, once CD19 is downregulated in plasma cells, through increased uptake of amino acids. One of the two mTOR complexes, mTORC1, promotes cell proliferation, survival, protein synthesis, cell migration and autophagy. mTORC1 is inhibited by AMPK or hypoxia [240]. In Saccharomyces cerevisiae, Drosophila melanogaster, and Mus musculus, reduction of mTOR signaling was shown to prolong their lifespan [185,241,242]. Benefits of caloric restrictions in delaying ageassociated impairments are also linked to suppression of the mTOR pathway [243]. mTOR is thought to contribute to aging by promoting protein synthesis. Expression levels of chaperons and their functions, which are essential to ensure correct protein folding, decline with age resulting in an accumulation of misfolded proteins [244,245]. Cells remove damaged or misfolded proteins by autophagy, which also becomes impaired with aging [11]. This is problematic for aged plasma cells, which produce thousands of antibody molecules per second as accumulation of misfolded antibodies in the ER will lead to their death. The constant region 
of the heavy chain of antibodies is glycosylated. Due to somatic hypermutations a fraction of antibodies also carries sugar residues in their variable region. Proteins largely undergo post-translational modifications within the cell, but antibodies can further be modified in plasma by $\beta 4$ galactosyltransferase (B4GALT) and a2,6-sialyltransferase (ST6GAL1). Glycosylation patterns of antibodies change with age, which affects antibody functions and contributes to enhanced inflammation. This is in part linked to an age-associated increase in the activity of B4GALT [246,247].

Mitochondrial functions decline with age. B cells during activation enhance mitochondrial OXPHOS to support their proliferation and effector functions. However, this increase is dampened in older adults as was shown in both mice and humans [248,249]. Instead, during activation aged B cells rely more on glycolysis for energy production. Glycolysis has been shown to favor plasma cell development rather than class switch reactions and somatic hypermutations, thus resulting in lower avidity antibody responses. This is further aggravated by the transcriptional profile of aged B cells that are undergoing stimulation. Compared to young B cells, those from the aged adults show declines in IRF8 and PRDM1 transcripts and increases in IRF4, BACH2 and XBP1 [208], which is a transcriptional profile that is typical for B cells undergoing plasma cell differentiation rather than affinity maturation. Loss of mitochondria functions not only affect the B cells' energy production and fate decisions but may also contribute to inflammaging. Damage-associated molecular patterns (DAMPs) released from broken mitochondria can trigger activation of the nuclear factor kappa B (NF-kB), activator protein 1 (AP-1), IRF7 and IRF3 pathways resulting in an inflammatory response [250]. Chronic inflammation with increased circulating levels of cytokines such as TNF, type I IFN and IL-6 tends to reduce antibody responses but this has to be investigated more thoroughly in the context of aging [251]. A subset of B cells congregates in adipose tissues within so-called fat-associated lymphoid clusters (FALC). The population of adipose tissue resident B cells increases with age under the influence of DAMP- and microbiota-derived PAMP-driven inflammasome activation. These B cells, which phenotypically belong to the memory subset, secrete pro-inflammatory cytokines that further contributing to inflammaging [252]. 


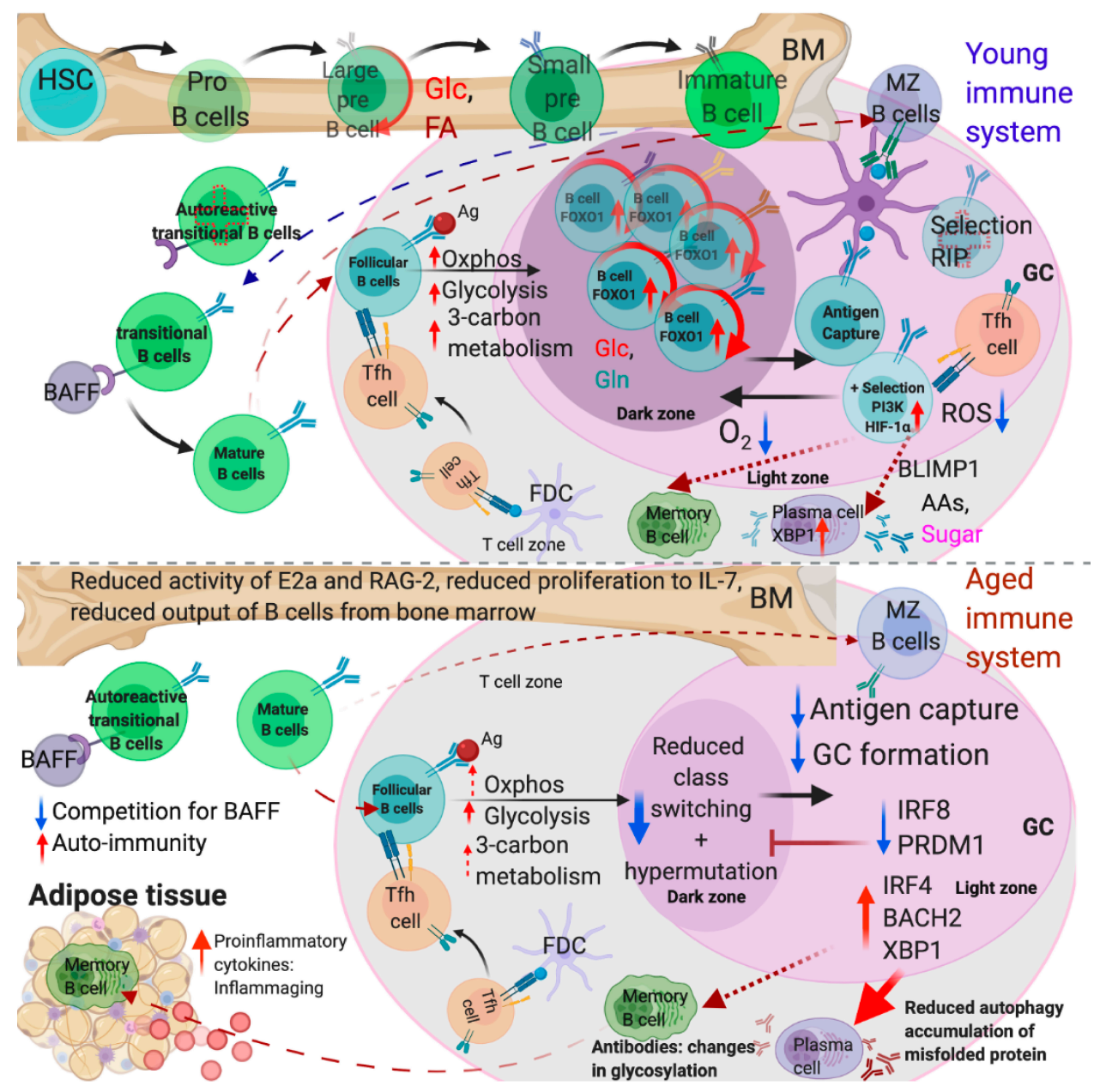

Figure 2. Impact of aging on B cell differentiation, function and metabolism. B cell differentiation and their metabolism in the young (upper panel) and older adults (lower panel). Tfh: follicular helper T cells; FDC: follicular dendritic cells; GC: germinal center; BM: bone marrow; Ag: antigen; RIP: "rest in peace"cells undergoing cell death. *Created with Biorender.com (https://biorender.com/).

Some of the key mitochondrial proteins that control OXPHOS are encoded by mitochondrial DNA (mtDNA), which during aging accumulate point mutations and deletions [253]. These mutations are most likely not caused by oxidative stress, as was originally thought [254]. Mutations, which affect individual mitochondria, can cause focal dysfunctions in OXPHOS over time. Affected cells initially compensate for defective mitochondria by increased mitochondrial biogenesis, which declines with aging in part due to lowered expression of SIRT1. Transcriptional regulation of SIRT1 involves many of the pathways that control B cell fate decision, so one would assume that this deacetylase plays a role in B cell differentiation. We found a reduction in SIRT1 in circulating aged as compared to young plasma cells [249]. Due to lower SIRT1 levels, the activity of the pyruvate dehydrogenase complex (PDC), which converts pyruvate into acetyl-CoA, is reduced in aged B cells. Reduced PDC activity may affect the survival of long-lived plasma cells [255], which rely on pyruvate-dependent respiration to meet their bioenergetic needs [179]. SIRT1 inhibits NF- $\kappa B$ activity and in most tissues decreases glycolysis and 
promotes fatty acid catabolism. Accordingly, although plasma cells compared to resting B cell subsets show increased uptake of fatty acids and enhanced levels of Cpt1, which is essential to transfer fatty acids into mitochondria, levels of fatty acid uptake and catabolism are attenuated in the aged plasma cells. We observed defects in two other metabolic pathways in aged B cells. One involves a reduction in the activity of AAC1, which converts acetyl-CoA to malonyl-CoA for fatty acid biosynthesis. Again, this pathway is essential for proliferating cells as it provides building blocks for cell membranes. Even more striking is the reduction in enzymes that function in one-carbon metabolism [249], an age-related change that was also observed in T cells [256]. One carbon metabolism supports biosynthesis of purines and thymidine, which are critical for DNA replication and transcription. One carbon metabolism is also essential for DNA repair, which is needed by B cells for Ig gene rearrangement during class-switching and DNA restoration following somatic hypermutations. Ig switching and the nonhomologous end-joining repair of the resulting DNA breaks involve a number of enzymes such as RAG-1 and -2, DNA ligases, X-Ray repair cross complementing (XRCC) 4 and 6, DNA-dependent protein kinases, the nuclease Artemis and terminal deoxynucleotidyl transferase. DNA repair further elicits an ataxiatelangiectasia mutated (ATM)-mediated DNA damage response to at least temporarily halt cell cycling. The ATM-mediated DNA damage response declines in older adults again depriving them of optimal antibody responses [257].

\section{STRATEGIES TO OVERCOME METABOLISM-RELATED DEFECTS IN AGED T AND B CELLS}

Is there a way to change age-related metabolic defects that result in declining $\mathrm{B}$ and $\mathrm{T}$ cell functions to render older adults at least temporarily more resistant to infections and more responsive to vaccines? One possible avenue would be to reduce inflammaging. Glycogen synthase kinase 3 (GSK3) regulates multiple pathways, such as NF-םB that lead to inflammatory cytokine production [258]. GSK3 also affects glucose metabolism, autophagy and apoptosis and is involved in regulating the circadian rhythm [259], which all affect immune responses. Lithium, a drug that has been used for years to treat bipolar disorder, is a GSK3 inhibitor and could be explored to reduce inflammaging [260,261]. Rapamycin, an mTOR inhibitor was initially used as immunosuppressor. It was subsequently shown to reduce inflammation and function as an immunomodulator by enhancing memory T cell response [262]. Clinical studies have shown that a cohort of aged individuals that were treated with rapamycin reported reduced rates of infections and showed higher responses to vaccines [263]. In addition, immune cell metabolism and functions are in part controlled by epigenetic changes. SIRTs through deacetylation regulate gene expression and thereby immune responses. SIRT1 inhibits the NF-kB pathway and in doing so reduces 
inflammation [264]. It also serves a negative regulator of Th1, Th2 and Treg cell activation but seems to improve $\mathrm{CD}^{+} \mathrm{T}$ cell functions by enhancing transcription of T-bet [265]. Little is known about the effect of SIRTs on B cells but SIRT1 seems to increase B cell survival [266]. Resveratrol, an activator of Sirt1 is under scrutiny as potential immune modulator and may prove to be useful as an agent to combat autoimmune diseases and inflammaging [265].

Beyond strategies to attenuate inflammation, caloric restriction has been shown to increase life span in many species [231]. Expression of SIRTs could increase upon caloric restriction, therefore reducing inflammation in older adults [267]. A recent study further suggested that dietary restriction through reducing the activity of a conserved innate immunity pathway mediated by p38 signaling, and the activating transcription factor (ATF)-7 reduces inflammation and may preserve immune cell functions [268]. Indeed, caloric restriction in non-human primates increases numbers of naive T cells, TCR repertoire diversity, and immune cell functions [179,269]. A short period of caloric restriction in older adults may also provide beneficial effects by improving immune functions. Finally, the immunological processes are sophisticatedly interconnected with various metabolic checkpoints that support immune cell functions [270]. Development of novel strategies that could directly modulate the metabolic processes could be exploited to manipulate immune responses and reduce age-associated immune dysfunctions.

\section{SUMMARY}

Immunosenescence, the gradual decline of the immune system upon aging, in part relates to accumulating metabolic defects. Chronic low-grade inflammation, which is common in the elderly, induces metabolic changes in lymphocytes that impair their ability to become activated, and then to proliferate and assume effector function or develop into memory cells. Intrinsic key metabolic pathways deteriorate in aging lymphocytes. Most notably, mitochondria become dysfunctional resulting in reduced energy production through OXPHOS and enhanced ROS production. The decline in mitochondrial functions drives cellular senescence and enhances chronic inflammation. Declining energy production further affects anabolic reaction, e.g., protein and fatty acid synthesis, impairing the functions of immune cells. The glycosylation patterns of proteins change, which influences their functions. The autophagy machinery becomes impaired, which robs cells of the ability to recycle or eliminate faulty proteins. Although nothing but premature death or being a Turritopsis dohrnii jellyfish, the only species that is virtually immortal by being able to transform from an adult form back to a juvenile polyp stage [271], can prevent or reverse aging [272], its detrimental effects on T and B cell responses can at least in part be negated by a balanced diet that includes vitamins and trace elements and regular exercise [273]. 


\section{AUTHOR CONTRIBUTIONS}

Both authors contributed equally to the writing of the manuscript.

\section{CONFLICTS OF INTEREST}

The authors have no conflicts of interest to declare.

\section{ACKNOWLEDGMENTS}

The authors would like to acknowledge the support of the Department of Defense, grant W81XWH-19-1-0485 CA180191, and Department of Defense Breast Cancer Breakthrough Fellowship Award awarded to Ying Zhang.

\section{REFERENCES}

1. Rose MR, Mueller LD. Evolution of human lifespan: Past, future, and present. Am J Hum Biol. 1998;10:409-20.

2. Burnet FM. Intrinsic mutagenesis: a genetic basis of ageing. Pathology. 1974;6:1-11. doi: 10.3109/00313027409077150

3. Oregl LE. The maintenance of the accuracy of protein synthesis and its relevance to ageing. Proc Natl Acad Sci U S A. 1963;49:517-21. doi: 10.1073/pnas.49.4.517

4. Harman D. Free radical theory of aging: an update: increasing the functional life span. Ann N Y Acad Sci. 2006;1067:10-21. doi: 10.1196/annals.1354.003

5. Cerami A. Hypothesis. Glucose as a mediator of aging. J Am Geriatr Soc. 1985;33:626-34. doi: 10.1111/j.1532-5415.1985.tb06319.x

6. Williams GC. Pleiotropy, Natural Selection, and the Evolution of Senescence. Evolution. 1957;11(4):398.

7. Kirkwood TB. Evolution of ageing. Nature. 1977;270(5635):301-4.

8. Brooks-Wilson AR. Genetics of healthy aging and longevity. Hum Genet. 2013;132(12):1323-38.

9. Taormina G, Mirisola MG. Calorie restriction in mammals and simple model organisms. Biomed Res Int. 2014;2014(14):308690-10.

10. Papadopoli D, Boulay K, Kazak L, Pollak M, Mallette F, Topisirovic I, et al. mTOR as a central regulator of lifespan and aging. F1000Res. 2019;8:998. doi: 10.12688/f1000research.17196.1

11. Barbosa MC, Grosso RA, Fader CM. Hallmarks of Aging: An Autophagic Perspective. Front Endocrinol. 2018;9:790. doi: 10.3389/fendo.2018.00790

12. Rogers RP, Rogina B. The role of INDY in metabolism, health and longevity. Front Genet. 2015;6:204. doi: 10.3389/fgene.2015.00204

13. Hayflick L, Moorhead PS. The serial cultivation of human diploid cell strains. Exp Cell Res. 1961;25:585-621. doi: 10.1016/0014-4827(61)90192-6

14. Herbig U, Ferreira M, Condel L, Carey D, Sedivy JM. Cellular senescence in aging primates. Science. 2006;31:1257-7. doi: 10.1126/science.1122446

15. Jurk D, Wilson C, Passos JF, Oakley F, Correia-Melo C, Greaves L, et al. Chronic inflammation induces telomere dysfunction and accelerates ageing in mice. Nat Commun. 2014;2:4172-14. doi: 10.1038/ncomms5172 
16. Albala C, Sánchez H, Lera L, Angel B, Cea X. Socioeconomic inequalities in active life expectancy and disability related to obesity among older people. Rev Med Chil. 2011;139:1276-85.

17. Fraga MF, Ballestar E, Paz MF, Ropero S, Setien F, Ballestar ML, et al. Epigenetic differences arise during the lifetime of monozygotic twins. Proc Natl Acad Sci U S A. 2005;102:10604-9. doi: 10.1073/pnas.0500398102

18. Roberts SB, Rosenberg I. Nutrition and aging: changes in the regulation of energy metabolism with aging. Physiol Rev. 2006;86:651-67. doi: 10.1152/physrev.00019.2005

19. Hood S, Amir S. The aging clock: circadian rhythms and later life. J Clin Invest. 2017;127:437-46. doi: 10.1172/JCI90328

20. Reaven GM, Reaven EP. Effects of age on various aspects of glucose and insulin metabolism. Mol Cell Biochem. 1980;31:37-47. doi: 10.1007/bf00817889

21. Toth MJ, Tchernof A. Lipid metabolism in the elderly. Eur J Clin Nutr. 2000;54(Suppl 3):S121-5. doi: 10.1038/sj.ejcn.1601033

22. Dardevet D, Sornet C, Balage M, Grizard J. Stimulation of in vitro rat muscle protein synthesis by leucine decreases with age. J Nutr. 2000;130:2630-5. doi: 10.1093/jn/130.11.2630

23. Foster AD, Sivarapatna A, Gress RE. The aging immune system and its relationship with cancer. Aging health. 2011 Oct 1;7(5):707-18.

24. Fulton RB, Varga SM. Effects of aging on the adaptive immune response to respiratory virus infections. Aging Health. 2009;5(6):775-87.

25. Ponnappan S, Ponnappan U. Aging and immune function: molecular mechanisms to interventions. Antioxid Redox Signal. 2011;14(8):1551-85.

26. Palmer S, Albergante L, Blackburn CC, Newman TJ. Thymic involution and rising disease incidence with age. Proc Natl Acad Sci U S A. 2018 Feb 20;115(8):1883-8.

27. Kumar BV, Connors TJ, Farber DL. Human T Cell Development, Localization, and Function throughout Life. Immunity. 2018;48(2):202-13.

28. Tai Y, Wang Q, Korner H, Zhang L, Wei W. Molecular Mechanisms of T Cells Activation by Dendritic Cells in Autoimmune Diseases. Front Pharmacol. 2018;9:642.

29. Curtsinger JM, Schmidt CS, Mondino A, Lins DC, Kedl RM, Jenkins MK, et al. Inflammatory cytokines provide a third signal for activation of naive $\mathrm{CD} 4^{+}$ and CD8 ${ }^{+}$T cells. J Immunol. 1999;162(6):3256-62.

30. Zhu J, Yamane H, Paul WE. Differentiation of effector CD4 T cell populations (*). Annu Rev Immunol. 2010;28(1):445-89.

31. Cox MA, Harrington LE, Zajac AJ. Cytokines and the inception of CD8 T cell responses. Trends Immunol. 2011;32(4):180-6.

32. Zhang N, Bevan MJ. CD8(+) T cells: foot soldiers of the immune system. Immunity. 2011;35(2):161-8.

33. Bhat $\mathrm{P}$, Leggatt $\mathrm{G}$, Waterhouse $\mathrm{N}$, Frazer IH. Interferon- $\gamma$ derived from cytotoxic lymphocytes directly enhances their motility and cytotoxicity. Cell Death Dis. 2017;8(6):e2836-6. 
34. Youngblood B, Hale JS, Kissick HT, Ahn E, Xu X, Wieland A, et al. Effector CD8 $\mathrm{T}$ cells dedifferentiate into long-lived memory cells. Nature. 2017;552(7685):404-9.

35. Saeidi A, Zandi K, Cheok YY, Saeidi H, Wong WF, Lee CYQ, et al. T-Cell Exhaustion in Chronic Infections: Reversing the State of Exhaustion and Reinvigorating Optimal Protective Immune Responses. Front Immunol. 2018;9:2569.

36. Chiba A, Murayama G, Miyake S. Mucosal-Associated Invariant T Cells in Autoimmune Diseases. Front Immunol. 2018;9:1333.

37. Tilloy F, Treiner E, Park SH, Garcia C, Lemonnier F, la Salle de H, et al. An invariant $\mathrm{T}$ cell receptor alpha chain defines a novel TAP-independent major histocompatibility complex class Ib-restricted alpha/beta T cell subpopulation in mammals. J Exp Med. 1999;189(12):1907-21.

38. Zinser ME, Highton AJ, Kurioka A, Kronsteiner B, Hagel J, Leng T, et al. Human MAIT cells show metabolic quiescence with rapid glucose-dependent upregulation of granzyme B upon stimulation. Immunol Cell Biol. 2018;96(6):666-74.

39. O'Brien A, Loftus RM, Pisarska MM, Tobin LM, Bergin R, Wood NAW, et al. Obesity Reduces mTORC1 Activity in Mucosal-Associated Invariant T Cells, Driving Defective Metabolic and Functional Responses. J Immunol. 2019;202(12):3404-11.

40. Maciver NJ, Michalek RD, Rathmell JC. Metabolic regulation of T lymphocytes. Annu Rev Immunol. 2013;31(1):259-83.

41. Michalek RD, Rathmell JC. The metabolic life and times of a T-cell. Immunol Rev. 2010;236(1):190-202.

42. Jones RG, Thompson CB. Revving the engine: signal transduction fuels $\mathrm{T}$ cell activation. Immunity. 2007;27(2):173-8.

43. Bantug GR, Galluzzi L, Kroemer G, Hess C. The spectrum of T cell metabolism in health and disease. Nat Rev Immunol. 2018;18(1):19-34.

44. van der Windt GJW, Pearce EL. Metabolic switching and fuel choice during Tcell differentiation and memory development. Immunol Rev. 2012;249(1):2742.

45. Jacobs SR, Herman CE, Maciver NJ, Wofford JA, Wieman HL, Hammen JJ, et al. Glucose uptake is limiting in T cell activation and requires CD28-mediated Akt-dependent and independent pathways. J Immunol. 2008;180(7):4476-86.

46. Fischer HJ, Sie C, Schumann E, Witte A-K, Dressel R, van den Brandt J, et al. The Insulin Receptor Plays a Critical Role in T Cell Function and Adaptive Immunity. J Immunol. 2017;198(5):1910-20.

47. Maratou E, Dimitriadis G, Kollias A, Boutati E, Lambadiari V, Mitrou P, et al. Glucose transporter expression on the plasma membrane of resting and activated white blood cells. Eur J Clin Invest. 2007;37(4):282-90.

48. Glick GD, Rossignol R, Lyssiotis CA, Wahl D, Lesch C, Sanchez B, et al. Anaplerotic metabolism of alloreactive $T$ cells provides a metabolic approach to treat graft-versus-host disease. J Pharmacol Exp Ther. 2014;351(2):298-307.

49. Ren W, Liu G, Yin J, Tan B, Wu G, Bazer FW, et al. Amino-acid transporters in T-cell activation and differentiation. Cell Death Dis. 2017;8(3):e2655-5. 
50. Altman BJ, Stine ZE, Dang CV. From Krebs to clinic: glutamine metabolism to cancer therapy. Nat Rev Cancer. 2016;16(12):773-3.

51. Metallo CM, Gameiro PA, Bell EL, Mattaini KR, Yang J, Hiller K, et al. Reductive glutamine metabolism by IDH1 mediates lipogenesis under hypoxia. Nature. 2011;481(7381):380-4.

52. DeBerardinis RJ, Lum JJ, Hatzivassiliou G, Thompson CB. The biology of cancer: metabolic reprogramming fuels cell growth and proliferation. Cell Metab. 2008;7(1):11-20.

53. Wang R, Dillon CP, Shi LZ, Milasta S, Carter R, Finkelstein D, et al. The transcription factor Myc controls metabolic reprogramming upon $\mathrm{T}$ lymphocyte activation. Immunity. 2011;35(6):871-82.

54. Rathmell JC. T cell Myc-tabolism. Immunity. 2011;35(6):845-6.

55. Delgoffe GM, Pollizzi KN, Waickman AT, Heikamp E, Meyers DJ, Horton MR, et al. The kinase mTOR regulates the differentiation of helper $\mathrm{T}$ cells through the selective activation of signaling by mTORC1 and mTORC2. Nat Immunol. 2011;12(4):295-303.

56. Pollizzi KN, Patel CH, Sun I-H, Oh M-H, Waickman AT, Wen J, et al. mTORC1 and mTORC2 selectively regulate $\mathrm{CD}^{+} \mathrm{T}$ cell differentiation. J Clin Invest. 2015;125(5):2090-108.

57. Ray JP, Staron MM, Shyer JA, Ho P-C, Marshall HD, Gray SM, et al. The Interleukin-2-mTORc1 Kinase Axis Defines the Signaling, Differentiation, and Metabolism of $\mathrm{T}$ Helper 1 and Follicular B Helper $\mathrm{T}$ Cells. Immunity. 2015;43(4):690-702.

58. Zeng H, Cohen S, Guy C, Shrestha S, Neale G, Brown SA, et al. mTORC1 and mTORC2 Kinase Signaling and Glucose Metabolism Drive Follicular Helper T Cell Differentiation. Immunity. 2016;45(3):540-54.

59. Finlay D, Cantrell DA. Metabolism, migration and memory in cytotoxic T cells. Nat Rev Immunol. 2011;11(2):109-17.

60. Rathmell JC, Fox CJ, Plas DR, Hammerman PS, Cinalli RM, Thompson CB. Aktdirected glucose metabolism can prevent Bax conformation change and promote growth factor-independent survival. Mol Cell Biol. 2003;(20):7315-28.

61. Edinger AL, Thompson CB. Akt maintains cell size and survival by increasing mTOR-dependent nutrient uptake. Mol Biol Cell. 2002;13(7):2276-88.

62. Miyamoto S, Murphy AN, Brown JH. Akt mediates mitochondrial protection in cardiomyocytes through phosphorylation of mitochondrial hexokinase-II. Cell Death Differ. 2008;15(3):521-9.

63. Porstmann T, Santos CR, Griffiths B, Cully M, Wu M, Leevers S, et al. SREBP activity is regulated by mTORC1 and contributes to Akt-dependent cell growth. Cell Metab. 2008;8(3):224-36.

64. DeBerardinis RJ, Lum JJ, Thompson CB. Phosphatidylinositol 3-kinasedependent modulation of carnitine palmitoyltransferase $1 \mathrm{~A}$ expression regulates lipid metabolism during hematopoietic cell growth. J Biol Chem. 2006;281(49):37372-80.

65. Michalek RD, Gerriets VA, Nichols AG, Inoue M, Kazmin D, Chang C-Y, et al. Estrogen-related receptor- $\alpha$ is a metabolic regulator of effector T-cell 
activation and differentiation. Proc Natl Acad Sci U S A. 2011;108(45):1834853.

66. Bensinger SJ, Bradley MN, Joseph SB, Zelcer N, Janssen EM, Hausner MA, et al. LXR signaling couples sterol metabolism to proliferation in the acquired immune response. Cell. 2008;134(1):97-111.

67. Michalek RD, Gerriets VA, Jacobs SR, Macintyre AN, MacIver NJ, Mason EF, et al. Cutting Edge: Distinct Glycolytic and Lipid Oxidative Metabolic Programs Are Essential for Effector and Regulatory CD4 ${ }^{+} \mathrm{T}$ Cell Subsets. J Immunol. 2011;186(6):3299-303.

68. Shi LZ, Wang R, Huang G, Vogel P, Neale G, Green DR, et al. HIF1alphadependent glycolytic pathway orchestrates a metabolic checkpoint for the differentiation of TH17 and Treg cells. J Exp Med. 2011;208(7):1367-76.

69. He N, Fan W, Henriquez B, Yu RT, Atkins AR, Liddle C, et al. Metabolic control of regulatory T cell (Treg) survival and function by Lkb1. Proc Natl Acad Sci U S A. 2017;114(47):12542-7.

70. Finlay DK, Rosenzweig E, Sinclair LV, Feijoo-Carnero C, Hukelmann JL, Rolf J, et al. PDK1 regulation of mTOR and hypoxia-inducible factor 1 integrate metabolism and migration of CD8+ T cells. J Exp Med. 2012 Dec 17;209(13):2441-53.

71. Loh L, Gherardin NA, Sant S, Grzelak L, Crawford JC, Bird NL, et al. Human Mucosal-Associated Invariant T Cells in Older Individuals Display Expanded TCRa $\beta$ Clonotypes with Potent Antimicrobial Responses. J Immunol. 2020;204(5):1119-33.

72. Shimobayashi M, Hall MN. Multiple amino acid sensing inputs to mTORC1. Cell Res. 2016;26(1):7-20.

73. O’Sullivan D, van der Windt GJW, Huang SC-C, Curtis JD, Chang C-H, Buck MD, et al. Memory CD8(+) T cells use cell-intrinsic lipolysis to support the metabolic programming necessary for development. Immunity. 2014;41(1):75-88.

74. Pearce EL, Walsh MC, Cejas PJ, Harms GM, Shen H, Wang L-S, et al. Enhancing CD8 T-cell memory by modulating fatty acid metabolism. Nature. 2009;460(7251):103-7.

75. Araki K, Turner AP, Shaffer VO, Gangappa S, Keller SA, Bachmann MF, et al. mTOR regulates memory CD8 T-cell differentiation. Nature. 2009;460(7251):108-12.

76. Hardie DG. AMP-activated protein kinase: a cellular energy sensor with a key role in metabolic disorders and in cancer. Biochem Soc Trans. 2011;39(1):1-13. doi: 10.1042/BST0390001

77. Buck MD, O'Sullivan D, Klein Geltink RI, Curtis JD, Chang C-H, Sanin DE, et al. Mitochondrial Dynamics Controls $\mathrm{T}$ Cell Fate through Metabolic Programming. Cell. 2016;166(1):63-76.

78. Sallusto F, Geginat J, Lanzavecchia A. Central memory and effector memory T cell subsets: function, generation, and maintenance. Annu Rev Immunol. 2004;22(1):745-63. 
79. Sathaliyawala T, Kubota M, Yudanin N, Turner D, Camp P, Thome JJC, et al. Distribution and compartmentalization of human circulating and tissueresident memory T cell subsets. Immunity. 2013;38(1):187-97.

80. Gehad A, Teague JE, Matos TR, Huang V, Yang C, Watanabe R, et al. A primary role for human central memory cells in tissue immunosurveillance. Blood Adv. 2018;2(3):292-8.

81. Phan AT, Doedens AL, Palazon A, Tyrakis PA, Cheung KP, Johnson RS, et al. Constitutive Glycolytic Metabolism Supports CD8 ${ }^{+} \mathrm{T}$ Cell Effector Memory Differentiation during Viral Infection. Immunity. 2016;45(5):1024-37.

82. Graef P, Buchholz VR, Stemberger C, Flossdorf M, Henkel L, Schiemann M, et al. Serial transfer of single-cell-derived immunocompetence reveals stemness of CD8(+) central memory T cells. Immunity. 2014;41(1):116-26.

83. Szabo PA, Miron M, Farber DL. Location, location, location: Tissue resident memory T cells in mice and humans. Sci Immunol. 2019;4(34):eaas9673.

84. Fonseca R, Beura LK, Quarnstrom CF, Ghoneim HE, Fan Y, Zebley CC, et al. Developmental plasticity allows outside-in immune responses by resident memory T cells. Nat Immunol. 2020;21(4):412-21.

85. Pan Y, Tian T, Park CO, Lofftus SY, Mei S, Liu X, et al. Survival of tissue-resident memory $\mathrm{T}$ cells requires exogenous lipid uptake and metabolism. Nature. 2017;543(7644):252-6.

86. Gubser PM, Bantug GR, Razik L, Fischer M, Dimeloe S, Hoenger G, et al. Rapid effector function of memory $\mathrm{CD}^{+} \mathrm{T}$ cells requires an immediate-early glycolytic switch. Nat Immunol. 2013;14(10):1064-72.

87. Balmer ML, Ma EH, Bantug GR, Grählert J, Pfister S, Glatter T, et al. Memory CD8+ T Cells Require Increased Concentrations of Acetate Induced by Stress for Optimal Function. Immunity. 2016;44(6):1312-24.

88. Zheng Y, Delgoffe GM, Meyer CF, Chan W, Powell JD. Anergic T cells are metabolically anergic. J Immunol. 2009;183(10):6095-101.

89. Wherry EJ. T cell exhaustion. Nat Immunol. 2011;131(6):492-9.

90. Zhang Y, Kurupati R, Liu L, Zhou XY, Zhang G, Hudaihed A, et al. Enhancing $\mathrm{CD}^{+} \mathrm{T}$ Cell Fatty Acid Catabolism within a Metabolically Challenging Tumor Microenvironment Increases the Efficacy of Melanoma Immunotherapy. Cancer Cell. 2017;32(3):377-9.

91. Wherry EJ, Ha S-J, Kaech SM, Haining WN, Sarkar S, Kalia V, et al. Molecular signature of $\mathrm{CD}^{+} \mathrm{T}$ cell exhaustion during chronic viral infection. Immunity. 2007;27(4):670-84.

92. Parry RV, Chemnitz JM, Frauwirth KA, Lanfranco AR, Braunstein I, Kobayashi SV, et al. CTLA-4 and PD-1 Receptors Inhibit T-Cell Activation by Distinct Mechanisms. Mol Cell Biol. 2005;25(21):9543-53.

93. Patsoukis N, Weaver JD, Strauss L, Herbel C, Seth P, Boussiotis VA. Immunometabolic Regulations Mediated by Coinhibitory Receptors and Their Impact on T Cell Immune Responses. Front Immunol. 2017;8(Suppl 1):330.

94. Patsoukis N, Bardhan K, Chatterjee P, Sari D, Liu B, Bell LN, et al. PD-1 alters T-cell metabolic reprogramming by inhibiting glycolysis and promoting lipolysis and fatty acid oxidation. Nat Commun. 2015;6:6692. 
95. Kedia-Mehta N, Finlay DK. Competition for nutrients and its role in controlling immune responses. Nat Commun. 2019;10(1):2123-8.

96. Annibaldi A, Widmann C. Glucose metabolism in cancer cells. Curr Opin Clin Nutr Metab Care. 2010;13(4):466-70.

97. Del Giudice G, Goronzy JJ, Grubeck-Loebenstein B, Lambert P-H, Mrkvan T, Stoddard JJ, et al. Fighting against a protean enemy: immunosenescence, vaccines, and healthy aging. NPJ Aging Mech Dis. 2018;4(1):1-8.

98. Nikolich-Žugich J. The twilight of immunity: emerging concepts in aging of the immune system. Nat Immunol. 2018;19(1):10-9.

99. Quinn KM, Palchaudhuri R, Palmer CS, La Gruta NL. The clock is ticking: the impact of ageing on $\mathrm{T}$ cell metabolism. Clin Transl Immunol. 2019;8(11):e01091.

100. López-Otín C, Blasco MA, Partridge L, Serrano M, Kroemer G. The hallmarks of aging. Cell. 2013;153(6):1194-217.

101. Hale JS, Boursalian TE, Turk GL, Fink PJ. Thymic output in aged mice. Proc Natl Acad Sci U S A. 2006;103(22):8447-52.

102. Braber den I, Mugwagwa T, Vrisekoop N, Westera L, Mögling R, de Boer AB, et al. Maintenance of peripheral naive T cells is sustained by thymus output in mice but not humans. Immunity. 2012;36(2):288-97.

103. Westera L, van Hoeven V, Drylewicz J, Spierenburg G, van Velzen JF, de Boer $\mathrm{RJ}$, et al. Lymphocyte maintenance during healthy aging requires no substantial alterations in cellular turnover. Aging Cell. 2015;14(2):219-27.

104. Goronzy JJ, Weyand CM. T cell development and receptor diversity during aging. Curr Opin Immunol. 2005;17(5):468-75.

105. Czesnikiewicz-Guzik M, Lee W-W, Cui D, Hiruma Y, Lamar DL, Yang Z-Z, et al. T cell subset-specific susceptibility to aging. Clin Immunol. 2008;127(1):107-18.

106. Pekalski ML, Ferreira RC, Coulson RMR, Cutler AJ, Guo H, Smyth DJ, et al. Postthymic expansion in human CD4 naive T cells defined by expression of functional high-affinity IL-2 receptors. J Immunol. 2013;190(6):2554-66.

107. van der Geest KSM, Abdulahad WH, Teteloshvili N, Tete SM, Peters JH, Horst G, et al. Low-affinity TCR engagement drives IL-2-dependent post-thymic maintenance of naive CD4 ${ }^{+}$T cells in aged humans. Aging Cell. 2015;14(5):74453.

108. Goronzy JJ, Fang F, Cavanagh MM, Qi Q, Weyand CM. Naive T cell maintenance and function in human aging. J Immunol. 2015;194(9):4073-80.

109. Wertheimer AM, Bennett MS, Park B, Uhrlaub JL, Martinez C, Pulko V, et al. Aging and cytomegalovirus infection differentially and jointly affect distinct circulating T cell subsets in humans. J Immunol. 2014;192(5):2143-55.

110. Diversity and clonal selection in the human T-cell repertoire. Proc Natl Acad Sci U S A. 2014;111(36):13139-44.

111. Franceschi C, Campisi J. Chronic inflammation (inflammaging) and its potential contribution to age-associated diseases. J Gerontol A. 2014; 69(Suppl 1):S4-9.

112. Pawelec G. Immunosenenescence: role of cytomegalovirus. Exp Gerontol. 2014;54:1-5. 
113. Frasca D, Blomberg BB, Paganelli R. Aging, Obesity, and Inflammatory AgeRelated Diseases. Front Immunol. 2017;8:1745.

114. Bryl E, Vallejo AN, Weyand CM, Goronzy JJ. Down-regulation of CD28 expression by TNF-alpha. J Immunol. 2001;167(6):3231-8.

115. Goronzy JJ, Weyand CM. Successful and Maladaptive T Cell Aging. Immunity. 2017;46(3):364-78.

116. Palmer CS, Duette GA, Wagner MCE, Henstridge DC, Saleh S, Pereira C, et al. Metabolically active $\mathrm{CD}^{+} \mathrm{T}$ cells expressing Glut1 and OX40 preferentially harbor HIV during in vitro infection. FEBS Lett. 2017;591(20):3319-32.

117. Ron-Harel N, Sharpe AH, Haigis MC. Mitochondrial metabolism in T cell activation and senescence: a mini-review. Gerontology. 2015;61(2):131-8.

118. Briceño O, Lissina A, Wanke K, Afonso G, Braun von A, Ragon K, et al. Reduced naïve CD8(+) T-cell priming efficacy in elderly adults. Aging Cell. 2016;15(1):14-21.

119. Shen-Orr SS, Furman D, Kidd BA, Hadad F, Lovelace P, Huang Y-W, et al. Defective Signaling in the JAK-STAT Pathway Tracks with Chronic Inflammation and Cardiovascular Risk in Aging Humans. Cell Syst. 2016;3(4):374-4.

120. Pinti M, Appay V, Campisi J, Frasca D, Fülöp T, Sauce D, et al. Aging of the immune system: Focus on inflammation and vaccination. Eur J Immunol. 2016;46(10):2286-301.

121. Chen P, Deng W, Li D, Zeng T, Huang L, Wang Q, et al. Circulating MucosalAssociated Invariant $\mathrm{T}$ Cells in a Large Cohort of Healthy Chinese Individuals From Newborn to Elderly. Front Immunol. 2019;10:260.

122. van der Geest KSM, Kroesen B-J, Horst G, Abdulahad WH, Brouwer E, Boots AMH. Impact of Aging on the Frequency, Phenotype, and Function of CD161Expressing T Cells. Front Immunol. 2018;9:752.

123. Uranga RM, Keller JN. The Complex Interactions Between Obesity, Metabolism and the Brain. Front Neurosci. 2019;13:513.

124. Torrão RC, Bennett SJ, Brown JE, Griffiths HR. Does metabolic reprogramming underpin age-associated changes in T cell phenotype and function? Free Radic Biol Med. 2014;71:26-35.

125. Han JM, Patterson SJ, Speck M, Ehses JA, Levings MK. Insulin inhibits IL-10mediated regulatory $\mathrm{T}$ cell function: implications for obesity. J Immunol. 2014;192(2):623-9.

126. Eller K, Kirsch A, Wolf AM, Sopper S, Tagwerker A, Stanzl U, et al. Potential role of regulatory $\mathrm{T}$ cells in reversing obesity-linked insulin resistance and diabetic nephropathy. Diabetes. 2011;60(11):2954-62.

127. Winer S, Chan Y, Paltser G, Truong D, Tsui H, Bahrami J, et al. Normalization of obesity-associated insulin resistance through immunotherapy. Nat Med. 2009;15(8):921-9.

128. Uciechowski P, Kahmann L, Plümäkers B, Malavolta M, Mocchegiani E, Dedoussis G, et al. TH1 and TH2 cell polarization increases with aging and is modulated by zinc supplementation. Exp Gerontol. 2008;43(5):493-8. 
129. Elyahu Y, Hekselman I, Eizenberg-Magar I, Berner O, Strominger I, Schiller M, et al. Aging promotes reorganization of the CD4 T cell landscape toward extreme regulatory and effector phenotypes. Sci Adv. 2019;5(8):eaaw8330.

130. Menon S, Dibble CC, Talbott G, Hoxhaj G, Valvezan AJ, Takahashi H, et al. Spatial control of the TSC complex integrates insulin and nutrient regulation of mTORC1 at the lysosome. Cell. 2014;156(4):771-85.

131. Matarese G, Procaccini C, De Rosa V. At the crossroad of T cells, adipose tissue, and diabetes. Immunol Rev. 2012;249(1):116-34.

132. Schöttker B, Brenner H, Jansen EHJM, Gardiner J, Peasey A, Kubínová R, et al. Evidence for the free radical/oxidative stress theory of ageing from the CHANCES consortium: a meta-analysis of individual participant data. BMC Med. 2015;13(1):300-15.

133. Kim B-J, Lee SH, Koh J-M. Clinical insights into the kynurenine pathway in agerelated diseases. Exp Gerontol. 2020;130:110793.

134. Griffiths HR, Lunec J, Blake DR. Oxygen radical induced fluorescence in proteins; identification of the fluorescent tryptophan metabolite, $\mathrm{N}$-formyl kynurenine, as a biological index of radical damage. Amino Acids. 1992;3(2):183-94.

135. Macallan DC, Asquith B, Irvine AJ, Wallace DL, Worth A, Ghattas H, et al. Measurement and modeling of human $\mathrm{T}$ cell kinetics. Eur J Immunol. 2003;33(8):2316-26.

136. Lang A, Nikolich-Žugich J. Functional CD8 T cell memory responding to persistent latent infection is maintained for life. J Immunol. 2011;187(7):375968.

137. Fülöp T, Larbi A, Pawelec G. Human T cell aging and the impact of persistent viral infections. Front Immunol. 2013;4:271.

138. Klenerman P. The (gradual) rise of memory inflation. Immunol Rev. John Wiley \& Sons, Ltd; 2018 May 1;283(1):99-112.

139. Nikolich-Žugich J. Ageing and life-long maintenance of T-cell subsets in the face of latent persistent infections. Nat Rev Immunol. 2008;8(7):512-22.

140. Karrer U, Sierro S, Wagner M, Oxenius A, Hengel H, Koszinowski UH, et al. Memory inflation: continuous accumulation of antiviral $\mathrm{CD}^{+} \mathrm{T}$ cells over time. J Immunol. 2003;170(4):2022-9.

141. Herndler-Brandstetter D, Landgraf K, Tzankov A, Jenewein B, Brunauer R, Laschober GT, et al. The impact of aging on memory T cell phenotype and function in the human bone marrow. J Leukoc Biol. 2012;91(2):197-205.

142. Henson SM, Riddell NE, Akbar AN. Properties of end-stage human T cells defined by CD45RA re-expression. Curr Opin Immunol. 2012;24(4):476-81.

143. Geginat J, Lanzavecchia A, Sallusto F. Proliferation and differentiation potential of human $\mathrm{CD}^{+}$memory $\mathrm{T}$-cell subsets in response to antigen or homeostatic cytokines. Blood. 2003;101(11):4260-6.

144. Henson SM, Lanna A, Riddell NE, Franzese O, Macaulay R, Griffiths SJ, et al. p38 signaling inhibits mTORC1-independent autophagy in senescent human CD8 ${ }^{+}$T cells. J Clin Invest. 2014;124(9):4004-16. 
145. Gil A, Yassai MB, Naumov YN, Selin LK. Narrowing of human influenza A virus-specific $\mathrm{T}$ cell receptor $\alpha$ and $\beta$ repertoires with increasing age. J Virol. 2015;89(8):4102-16.

146. Blackman MA, Woodland DL. The narrowing of the CD8 T cell repertoire in old age. Curr Opin Immunol. 2011;23(4):537-42.

147. Tidwell TR, Søreide K, Hagland HR. Aging, Metabolism, and Cancer Development: from Peto's Paradox to the Warburg Effect. Aging Dis. 2017;8(5):662-76.

148. Trifunovic A, Wredenberg A, Falkenberg M, Spelbrink JN, Rovio AT, Bruder $\mathrm{CE}$, et al. Premature ageing in mice expressing defective mitochondrial DNA polymerase. Nature. 2004;429(6990):417-23.

149. Talens RP, Christensen K, Putter H, Willemsen G, Christiansen L, Kremer D, et al. Epigenetic variation during the adult lifespan: cross-sectional and longitudinal data on monozygotic twin pairs. Aging Cell. 2012;11(4):694-703.

150. Sahin E, Colla S, Liesa M, Moslehi J, Müller FL, Guo M, et al. Telomere dysfunction induces metabolic and mitochondrial compromise. Nature. 2011;470(7334):359-65.

151. Hipp MS, Kasturi P, Hartl FU. The proteostasis network and its decline in ageing. Nat Rev Mol Cell Biol. 2019;20(7):421-35.

152. Tomaru U, Takahashi S, Ishizu A, Miyatake Y, Gohda A, Suzuki S, et al. Decreased proteasomal activity causes age-related phenotypes and promotes the development of metabolic abnormalities. Am J Pathol. 2012;180(3):963-72.

153. Taylor RC, Dillin A. Aging as an event of proteostasis collapse. Cold Spring Harb Perspect Biol. 2011;3(5):a004440-0.

154. Stead ER, Castillo-Quan JI, Miguel VEM, Lujan C, Ketteler R, Kinghorn KJ, et al. Agephagy-Adapting Autophagy for Health During Aging. Front Cell Dev Biol. 2019;7:308.

155. Moskowitz DM, Zhang DW, Hu B, Le Saux S, Yanes RE, Ye Z, et al. Epigenomics of human CD8 $\mathrm{T}$ cell differentiation and aging. Sci Immunol. 2017;2(8):eaag0192.

156. Wu Z, Puigserver P, Andersson U, Zhang C, Adelmant G, Mootha V, et al. Mechanisms controlling mitochondrial biogenesis and respiration through the thermogenic coactivator PGC-1. Cell. 1999;98(1):115-24.

157. Defective respiration and one-carbon metabolism contribute to impaired naïve $\mathrm{T}$ cell activation in aged mice. Proc Natl Acad Sci U S A. 2018;115(52):13347-52.

158. Becklund BR, Purton JF, Ramsey C, Favre S, Vogt TK, Martin CE, et al. The aged lymphoid tissue environment fails to support naïve T cell homeostasis. Sci Rep. 2016;6(1):30842-12.

159. Lazuardi L, Jenewein B, Wolf AM, Pfister G, Tzankov A, Grubeck-Loebenstein B. Age-related loss of naïve $\mathrm{T}$ cells and dysregulation of T-cell/B-cell interactions in human lymph nodes. Immunology. 2005;114(1):37-43.

160. Xia F, Qian C-R, Xun Z, Hamon Y, Sartre A-M, Formisano A, et al. TCR and CD28 Concomitant Stimulation Elicits a Distinctive Calcium Response in Naive $\mathrm{T}$ Cells. Front Immunol. 2018;9:2864. 
161. Joseph N, Reicher B, Barda-Saad M. The calcium feedback loop and T cell activation: how cytoskeleton networks control intracellular calcium flux. Biochim Biophys Acta. 2014;1838(2):557-68.

162. Lee J-U, Kim L-K, Choi J-M. Revisiting the Concept of Targeting NFAT to Control T Cell Immunity and Autoimmune Diseases. Front Immunol. 2018;9:2747.

163. Utsuyama M, Wakikawa A, Tamura T, Nariuchi H, Hirokawa K. Impairment of signal transduction in T cells from old mice. Mech Ageing Dev. 1997;93(13):131-44.

164. Vaeth M, Feske S. NFAT control of immune function: New Frontiers for an Abiding Trooper. F1000 Res. 2018;7(260):260.

165. Phadwal K, Alegre-Abarrategui J, Watson AS, Pike L, Anbalagan S, Hammond EM, et al. A novel method for autophagy detection in primary cells: impaired levels of macroautophagy in immunosenescent $\mathrm{T}$ cells. Autophagy. 2012;8(4):677-89.

166. Puleston DJ, Zhang H, Powell TJ, Lipina E, Sims S, Panse I, et al. Autophagy is a critical regulator of memory CD8(+) T cell formation. Elife. 2014;3:2516.

167. Crooke A, Martínez-Henández J, Martínez-López J, Cruz-Jentoft A, Huete-Toral F, Pintor J. Low expression of CD39 and CD73 genes in centenarians compared with octogenarians. Immun Ageing. 2017;14(1):11-5.

168. Zhao H, Bo C, Kang Y, Li H. What Else Can CD39 Tell Us? Front Immunol. 2017;8:727.

169. Fang F, Yu M, Cavanagh MM, Hutter Saunders J, Qi Q, Ye Z, et al. Expression of CD39 on Activated T Cells Impairs their Survival in Older Individuals. Cell Rep. 2016;14(5):1218-31.

170. Lanna A, Gomes DCO, Muller-Durovic B, McDonnell T, Escors D, Gilroy DW, et al. A sestrin-dependent Erk-Jnk-p38 MAPK activation complex inhibits immunity during aging. Nat Immunol. 2017;18(3):354-63.

171. Yu M, Li G, Lee W-W, Yuan M, Cui D, Weyand CM, et al. Signal inhibition by the dual-specific phosphatase 4 impairs T cell-dependent B-cell responses with age. Proc Natl Acad Sci U S A. 2012;109(15):E879-88.

172. Davenport B, Eberlein J, van der Heide V, Jhun K, Nguyen TT, Victorino F, et al. Aging of Antiviral $\mathrm{CD}^{+}$Memory $\mathrm{T}$ Cells Fosters Increased Survival, Metabolic Adaptations, and Lymphoid Tissue Homing. J Immunol. 2019;202(2):460-75.

173. Schurich A, Pallett LJ, Jajbhay D, Wijngaarden J, Otano I, Gill US, et al. Distinct Metabolic Requirements of Exhausted and Functional Virus-Specific CD8 T Cells in the Same Host. Cell Rep. 2016;16(5):1243-52.

174. Weng N-P, Akbar AN, Goronzy J. CD28(-) T cells: their role in the ageassociated decline of immune function. Trends Immunol. 2009;30(7):306-12.

175. Martin MD, Badovinac VP. Defining Memory CD8 T Cell. Front Immunol. 2018;9:2692.

176. Jeng MY, Hull PA, Fei M, Kwon H-S, Tsou C-L, Kasler H, et al. Metabolic reprogramming of human CD8+ memory $\mathrm{T}$ cells through loss of SIRT1. J Exp Med. 2018;215(1):51-62. 
177. Tilly G, Doan-Ngoc T-M, Yap M, Caristan A, Jacquemont L, Danger R, et al. IL15 Harnesses Pro-inflammatory Function of TEMRA CD8 in KidneyTransplant Recipients. Front Immunol. 2017;8:778.

178. White MJ, Beaver CM, Goodier MR, Bottomley C, Nielsen CM, Wolf A-SFM, et al. Calorie Restriction Attenuates Terminal Differentiation of Immune Cells. Front Immunol. 2016;7(1A):667.

179. Messaoudi I, Warner J, Fischer M, Park B, Hill B, Mattison J, et al. Delay of T cell senescence by caloric restriction in aged long-lived nonhuman primates. Proc Natl Acad Sci U S A. 2006;103(51):19448-53.

180. Johnson SC, Rabinovitch PS, Kaeberlein M. mTOR is a key modulator of ageing and age-related disease. Nature. 2013;493(7432):338-45.

181. LeBien TW, Tedder TF. B lymphocytes: how they develop and function. Blood. 2008;112(5):1570-80.

182. Hardy RR, Hayakawa K. B cell development pathways. Annu Rev Immunol. 2001;19(1):595-621.

183. Pieper K, Grimbacher B, Eibel H. B-cell biology and development. J Allergy Clin Immunol. 2013;131(4):959-71.

184. Stein M, Dütting S, Mougiakakos D, Bösl M, Fritsch K, Reimer D, et al. A defined metabolic state in pre B cells governs B-cell development and is counterbalanced by Swiprosin-2/EFhd1. Cell Death Differ. 2017;24(7):1239-52.

185. Nemazee D. Mechanisms of central tolerance for B cells. Nat Rev Immunol. 2017;17(5):281-94.

186. Harless SM, Lentz VM, Sah AP, Hsu BL, Clise-Dwyer K, Hilbert DM, et al. Competition for BLyS-mediated signaling through Bcmd/BR3 regulates peripheral B lymphocyte numbers. Curr Biol. 2001;11(24):1986-9.

187. Pillai S, Cariappa A. The follicular versus marginal zone B lymphocyte cell fate decision. Nat Rev Immunol. 2009;9(11):767-77.

188. Lalor PA, Herzenberg LA, Adams S, Stall AM. Feedback regulation of murine Ly-1 B cell development. Eur J Immunol. 1989;19(3):507-13.

189. Graf R, Seagal J, Otipoby KL, Lam K-P, Ayoub S, Zhang B, et al. BCR-dependent lineage plasticity in mature B cells. Science. 2019;363(6428):748-53.

190. Cerutti A, Cols M, Puga I. Marginal zone B cells: virtues of innate-like antibodyproducing lymphocytes. Nat Rev Immunol. 2013;13(2):118-32.

191. Depoil D, Fleire S, Treanor BL, Weber M, Harwood NE, Marchbank KL, et al. CD19 is essential for B cell activation by promoting B cell receptor-antigen microcluster formation in response to membrane-bound ligand. Nat Immunol. 2008;9(1):63-72.

192. Jellusova J, Rickert RC. The PI3K pathway in B cell metabolism. Crit Rev Biochem Mol Biol. 2016;51(5):359-78.

193. Stebegg M, Kumar SD, Silva-Cayetano A, Fonseca VR, Linterman MA, Graca L. Regulation of the Germinal Center Response. Front Immunol. 2018;9:2469.

194. Shlomchik MJ, Luo W, Weisel F. Linking signaling and selection in the germinal center. Immunol Rev. 2019;288(1):49-63.

195. Crotty S. A brief history of $\mathrm{T}$ cell help to $\mathrm{B}$ cells. Nat Rev Immunol. 2015;15(3):185-9. 
196. Moens L, Tangye SG. Cytokine-Mediated Regulation of Plasma Cell Generation: IL-21 Takes Center Stage. Front Immunol. 2014;5:65.

197. Hua Z, Hou B. TLR signaling in B-cell development and activation. Cell Mol Immunol. 2013;10(2):103-6.

198. Huang C, Geng H, Boss I, Wang L, Melnick A. Cooperative transcriptional repression by BCL6 and BACH2 in germinal center B-cell differentiation. Blood. 2014;123(7):1012-20.

199. Shukla V, Lu R. IRF4 and IRF8: Governing the virtues of B Lymphocytes. Front Biol. 2014 Aug;9(4):269-82.

200. Tellier J, Shi W, Minnich M, Liao Y, Crawford S, Smyth GK, et al. Blimp-1 controls plasma cell function through the regulation of immunoglobulin secretion and the unfolded protein response. Nat Immunol. 2016;17(3):323-30.

201. Urbanczyk S, Stein M, Schuh W, Jäck H-M, Mougiakakos D, Mielenz D. Regulation of Energy Metabolism during Early B Lymphocyte Development. Int J Mol Sci. 2018;19(8):2192.

202. Khalsa JK, Chawla AS, Prabhu SB, Vats M, Dhar A, Dev G, et al. Functionally significant metabolic differences between $\mathrm{B}$ and $\mathrm{T}$ lymphocyte lineages. Immunology. 2019;158(2):104-20.

203. Marshall-Clarke S, Tasker L, Heaton MP, Parkhouse RME. A differential requirement for phosphoinositide 3-kinase reveals two pathways for inducible upregulation of major histocompatibility complex class II molecules and CD86 expression by murine B lymphocytes. Immunology. 2003;109(1):102-8.

204. Boothby M, Rickert RC. Metabolic Regulation of the Immune Humoral Response. Immunity. 2017;46(5):743-55.

205. Caro-Maldonado A, Gerriets VA, Rathmell JC. Matched and mismatched metabolic fuels in lymphocyte function. Semin Immunol. 2012;24(6):405-13.

206. Caro-Maldonado A, Wang R, Nichols AG, Kuraoka M, Milasta S, Sun LD, et al. Metabolic reprogramming is required for antibody production that is suppressed in anergic but exaggerated in chronically BAFF-exposed B cells. J Immunol. 2014;192(8):3626-36.

207. Doughty CA, Bleiman BF, Wagner DJ, Dufort FJ, Mataraza JM, Roberts MF, et al. Antigen receptor-mediated changes in glucose metabolism in $B$ lymphocytes: role of phosphatidylinositol 3-kinase signaling in the glycolytic control of growth. Blood. 2006;107(11):4458-65.

208. Waters LR, Ahsan FM, Wolf DM, Shirihai O, Teitell MA. Initial B Cell Activation Induces Metabolic Reprogramming and Mitochondrial Remodeling. ISCIENCE. 2018;5:99-109.

209. Jang K-J, Mano H, Aoki K, Hayashi T, Muto A, Nambu Y, et al. Mitochondrial function provides instructive signals for activation-induced B-cell fates. Nat Commun. 2015;6(1):6750.

210. Inoue T, Shinnakasu R, Ise W, Kawai C, Egawa T, Kurosaki T. The transcription factor Foxo1 controls germinal center B cell proliferation in response to T cell help. J Exp Med. 2017;214(4):1181-98. 
211. Cho SH, Raybuck AL, Stengel K, Wei M, Beck TC, Volanakis E, et al. Germinal centre hypoxia and regulation of antibody qualities by a hypoxia response system. Nature. 2016;537(7619):234-8.

212. Dominguez-Sola D, Kung J, Holmes AB, Wells VA, Mo T, Basso K, et al. The FOXO1 Transcription Factor Instructs the Germinal Center Dark Zone Program. Immunity. 2015;43(6):1064-74.

213. Sander S, Chu VT, Yasuda T, Franklin A, Graf R, Calado DP, et al. PI3 Kinase and FOX01 Transcription Factor Activity Differentially Control B Cells in the Germinal Center Light and Dark Zones. Immunity. 2015;43(6):1075-86.

214. Akkaya M, Traba J, Roesler AS, Miozzo P, Akkaya B, Theall BP, et al. Second signals rescue $B$ cells from activation-induced mitochondrial dysfunction and death. Nat Immunol. 2018;19(8):871-84.

215. Gray D. Is the survival of memory B cells dependent on the persistence of antigen? Adv Exp Med Biol. 1988;237(Chapter 30):203-7.

216. Chen M, Hong MJ, Sun H, Wang L, Shi X, Gilbert BE, et al. Essential role for autophagy in the maintenance of immunological memory against influenza infection. Nat Med. 2014;20(5):503-10.

217. Sandoval H, Kodali S, Wang J. Regulation of B cell fate, survival, and function by mitochondria and autophagy. Mitochondrion. 2018;41:58-65.

218. Lam WY, Becker AM, Kennerly KM, Wong R, Curtis JD, Llufrio EM, et al. Mitochondrial Pyruvate Import Promotes Long-Term Survival of AntibodySecreting Plasma Cells. Immunity. 2016;45(1):60-73.

219. Kim M, Qie Y, Park J, Kim CH. Gut Microbial Metabolites Fuel Host Antibody Responses. Cell Host Microbe. 2016;20(2):202-14.

220. Pengo N, Scolari M, Oliva L, Milan E, Mainoldi F, Raimondi A, et al. Plasma cells require autophagy for sustainable immunoglobulin production. Nat Immunol. 2013;14(3):298-305.

221. Singh R, Kaushik S, Wang Y, Xiang Y, Novak I, Komatsu M, et al. Autophagy regulates lipid metabolism. Nature. 2009;458(7242):1131-5.

222. Clarke AJ, Riffelmacher T, Braas D, Cornall RJ, Simon AK. B1a B cells require autophagy for metabolic homeostasis and self-renewal. J Exp Med. 2018;215(2):399-413.

223. Muri J, Thut H, Bornkamm GW, Kopf M. B1 and Marginal Zone B Cells but Not Follicular B2 Cells Require Gpx4 to Prevent Lipid Peroxidation and Ferroptosis. Cell Rep. 2019;29(9):2731-4.

224. Nakaya HI, Hagan T, Duraisingham SS, Lee EK, Kwissa M, Rouphael N, et al. Systems Analysis of Immunity to Influenza Vaccination across Multiple Years and in Diverse Populations Reveals Shared Molecular Signatures. Immunity. 2015;43(6):1186-98.

225. Kelvin DJ, Farooqui A. Extremely low vaccine effectiveness against influenza H3N2 in the elderly during the 2012/2013 flu season. J Infect Dev Ctries. 2013;7(3):299-301.

226. Min H, Montecino-Rodriguez E, Dorshkind K. Effects of aging on early B- and T-cell development. Immunol Rev. 2005;205(1):7-17. 
227. Rossi DJ, Bryder D, Zahn JM, Ahlenius H, Sonu R, Wagers AJ, et al. Cell intrinsic alterations underlie hematopoietic stem cell aging. Proc Natl Acad Sci U S A. 2005;102(26):9194-9.

228. Pioli PD, Casero D, Montecino-Rodriguez E, Morrison SL, Dorshkind K. Plasma Cells Are Obligate Effectors of Enhanced Myelopoiesis in Aging Bone Marrow. Immunity. 2019;51(2):351-6.

229. Labrie JE, Sah AP, Allman DM, Cancro MP, Gerstein RM. Bone marrow microenvironmental changes underlie reduced RAG-mediated recombination and B cell generation in aged mice. J Exp Med. 2004;200(4):41123.

230. Stephan RP, Lill-Elghanian DA, Witte PL. Development of B cells in aged mice: decline in the ability of pro-B cells to respond to IL-7 but not to other growth factors. J Immunol. 1997;158(4):1598-609.

231. Dorshkind K, Montecino-Rodriguez E, Signer RAJ. The ageing immune system: is it ever too old to become young again? Nat Rev Immunol. 2009;9(1):57-62.

232. Rodriguez-Zhurbenko N, Quach TD, Hopkins TJ, Rothstein TL, Hernandez AM. Human B-1 Cells and B-1 Cell Antibodies Change With Advancing Age. Front Immunol. 2019;10:483.

233. Turner VM, Mabbott NA. Ageing adversely affects the migration and function of marginal zone B cells. Immunology. 2017;151(3):349-62.

234. Guerrettaz LM, Johnson SA, Cambier JC. Acquired hematopoietic stem cell defects determine B-cell repertoire changes associated with aging. Proc Natl Acad Sci U S A. 2008;105(33):11898-902.

235. Zheng B, Han S, Takahashi Y, Kelsoe G. Immunosenescence and germinal center reaction. Immunol Rev. 1997;160(1):63-77.

236. Eaton SM, Burns EM, Kusser K, Randall TD, Haynes L. Age-related defects in CD4 $\mathrm{T}$ cell cognate helper function lead to reductions in humoral responses. J Exp Med. 2004;200(12):1613-22.

237. Shankwitz K, Pallikkuth S, Sirupangi T, Kirk Kvistad D, Russel KB, Pahwa R, et al. Compromised steady-state germinal center activity with age in nonhuman primates. Aging Cell. 2020;19(2):e13087.

238. Frasca D, Landin AM, Lechner SC, Ryan JG, Schwartz R, Riley RL, et al. Aging down-regulates the transcription factor E2A, activation-induced cytidine deaminase, and Ig class switch in human B cells. J Immunol. 2008;180(8):528390.

239. Limon JJ, Fruman DA. Akt and mTOR in B Cell Activation and Differentiation. Front Immunol. 2012;3:228.

240. Jhanwar-Uniyal M, Wainwright JV, Mohan AL, Tobias ME, Murali R, Gandhi CD, et al. Diverse signaling mechanisms of mTOR complexes: mTORC1 and mTORC2 in forming a formidable relationship. Adv Biol Regul. 2019;72:51-62.

241. Bjedov I, Toivonen JM, Kerr F, Slack C, Jacobson J, Foley A, et al. Mechanisms of life span extension by rapamycin in the fruit fly Drosophila melanogaster. Cell Metab. 2010 Jan;11(1):35-46.

242. Harrison DE, Strong R, Sharp ZD, Nelson JF, Astle CM, Flurkey K, et al. Rapamycin fed late in life extends lifespan in genetically heterogeneous mice. Nature. 2009;460(7253):392-5. 
243. Mattison JA, Colman RJ, Beasley TM, Allison DB, Kemnitz JW, Roth GS, et al. Caloric restriction improves health and survival of rhesus monkeys. Nat Commun. 2017;8(1):14063-12.

244. Estébanez B, de Paz JA, Cuevas MJ, González-Gallego J. Endoplasmic Reticulum Unfolded Protein Response, Aging and Exercise: An Update. Front Physiol. 2018;9:1744.

245. Soti C, Csermely P. Aging and molecular chaperones. Exp Gerontol. 2003;38(10):1037-40.

246. Catera M, Borelli V, Malagolini N, Chiricolo M, Venturi G, Reis CA, et al. Identification of novel plasma glycosylation-associated markers of aging. Oncotarget. 2016;7(7):7455-68.

247. Krištić J, Vučković F, Menni C, Klarić L, Keser T, Beceheli I, et al. Glycans are a novel biomarker of chronological and biological ages. J Gerontol A. 2014;69(7):779-89.

248. Kannan S, Dawany N, Kurupati R, Showe LC, Ertl HCJ. Age-related changes in the transcriptome of antibody-secreting cells. Oncotarget. 2016;7(12):13340 53.

249. Kurupati RK, Haut LH, Schmader KE, Ertl HC. Age-related changes in B cell metabolism. Aging. 2019;11(13):4367-81.

250. Zhang Q, Raoof M, Chen Y, Sumi Y, Sursal T, Junger W, et al. Circulating mitochondrial DAMPs cause inflammatory responses to injury. Nature. 2010;464(7285):104-7.

251. Parmigiani A, Alcaide ML, Freguja R, Pallikkuth S, Frasca D, Fischl MA, et al. Impaired antibody response to influenza vaccine in HIV-infected and uninfected aging women is associated with immune activation and inflammation. PLoS One. 2013;8(11):e79816.

252. Camell CD, Günther P, Lee A, Goldberg EL, Spadaro O, Youm Y-H, et al. Aging Induces an Nlrp3 Inflammasome-Dependent Expansion of Adipose B Cells That Impairs Metabolic Homeostasis. Cell Metab. 2019;30(6):1024-6.

253. Stewart JB, Chinnery PF. The dynamics of mitochondrial DNA heteroplasmy: implications for human health and disease. Nat Rev Genet. 2015;16(9):530-42.

254. Anson RM, Sentürker S, Dizdaroglu M, Bohr VA. Measurement of oxidatively induced base lesions in liver from Wistar rats of different ages. Free Radic Biol Med. 1999;27(3-4):456-62.

255. Jian B, Yang S, Chaudry IH, Raju R. Resveratrol restores sirtuin 1 (SIRT1) activity and pyruvate dehydrogenase kinase 1 (PDK1) expression after hemorrhagic injury in a rat model. Mol Med. 2014;20(1):10-6.

256. Ron-Harel N, Santos D, Ghergurovich JM, Sage PT, Reddy A, Lovitch SB, et al. Mitochondrial Biogenesis and Proteome Remodeling Promote One-Carbon Metabolism for T Cell Activation. Cell Metab. 2016;24(1):104-17.

257. Gutierrez-Martinez P, Hogdal L, Nagai M, Kruta M, Singh R, Sarosiek K, et al. Diminished apoptotic priming and ATM signalling confer a survival advantage onto aged haematopoietic stem cells in response to DNA damage. Nat Cell Biol. 2018;20(4):413-21. 
258. Beurel E, Michalek SM, Jope RS. Innate and adaptive immune responses regulated by glycogen synthase kinase-3 (GSK3). Trends Immunol. 2010;31(1):24-31.

259. Glycogen synthase kinase 3, circadian rhythms, and bipolar disorder: a molecular link in the therapeutic action of lithium. J Circadian Rhythms. 2007;5(0):3.

260. Souder DC, Anderson RM. An expanding GSK3 network: implications for aging research. Geroscience. 2019;41(4):369-82.

261. Lelegren M, Liu Y, Ross C, Tardif S, Salmon AB. Pharmaceutical inhibition of mTOR in the common marmoset: effect of rapamycin on regulators of proteostasis in a non-human primate. Pathobiol Aging Age Relat Dis. 2016;6(1):31793.

262. Gammon JM, Gosselin EA, Tostanoski LH, Chiu Y-C, Zeng X, Zeng Q, et al. Lowdose controlled release of mTOR inhibitors maintains $\mathrm{T}$ cell plasticity and promotes central memory T cells. J Control Release. 2017;263:151-61.

263. Mannick JB, Morris M, Hockey H-UP, Roma G, Beibel M, Kulmatycki K, et al. TORC1 inhibition enhances immune function and reduces infections in the elderly. Sci Transl Med. 2018;10(449):eaaq1564.

264. Kauppinen A, Suuronen T, Ojala J, Kaarniranta K, Salminen A. Antagonistic crosstalk between NF- $\kappa \mathrm{B}$ and SIRT1 in the regulation of inflammation and metabolic disorders. Cell Signal. 2013;25(10):1939-48.

265. Warren JL, Maciver NJ. Regulation of Adaptive Immune Cells by Sirtuins. Front Endocrinol. 2019;10:466.

266. Wang Q, Yan C, Xin M, Han L, Zhang Y, Sun M. Sirtuin 1 (Sirt1) Overexpression in BaF3 Cells Contributes to Cell Proliferation Promotion, Apoptosis Resistance and Pro-Inflammatory Cytokine Production. Med Sci Monit. 2017;23:1477-82.

267. Chen D, Guarente L. SIR2: a potential target for calorie restriction mimetics. Trends Mol Med. 2007;13(2):64-71.

268. Wu Z, Isik M, Moroz N, Steinbaugh MJ, Zhang P, Blackwell TK. Dietary Restriction Extends Lifespan through Metabolic Regulation of Innate Immunity. Cell Metab. 2019;29(5):1192-8.

269. Nikolich-Žugich J, Messaoudi I. Mice and flies and monkeys too: caloric restriction rejuvenates the aging immune system of non-human primates. Exp Gerontol. 2005;40(11):884-93.

270. Wang R, Green DR. Metabolic checkpoints in activated T cells. Nat Immunol. 2012;13(10):907-15.

271. Martell L, Piraino S, Gravili C, Boero F. Life cycle, morphology and medusa ontogenesis of Turritopsis dohrnii (Cnidaria: Hydrozoa). Ital J Zool. 2016;83(3):390-9.

272. Matsumoto Y, Piraino S, Miglietta MP. Transcriptome Characterization of Reverse Development in Turritopsis dohrnii (Hydrozoa, Cnidaria). G3 (Bethesda). 2019;9(12):4127-38.

273. Silva LCR, de Araújo AL, Fernandes JR, Matias M de ST, Silva PR, Duarte AJS, et al. Moderate and intense exercise lifestyles attenuate the effects of aging on 
telomere length and the survival and composition of $\mathrm{T}$ cell subpopulations. Age. 2016;38(1):24.

How to cite this article:

Zhang Y, Ertl HCJ. T and B cell Metabolism in Older Adults. Immunometabolism. 2020;2(3):e200021. https://doi.org/10.20900/immunometab20200021 